NATIONAL LABORATORY

MANAGED BY UT-BATTELLE

FOR THE DEPARTMENT OF ENERGY

\title{
Assessment of End-of-Life Behavior of the Surface Modification to Improve Cavitation-Erosion Resistance in the Mercury Target at the Spallation Neutron Source
}

S. J. PAWEL

June 2007

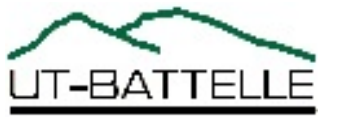




\title{
DOCUMENT AVAILABILITY
}

Reports produced after January 1, 1996, are generally available free via the U.S. Department of Energy (DOE) Information Bridge.

Web site http://www.osti.gov/bridge

Reports produced before January 1, 1996, may be purchased by members of the public from the following source.

\author{
National Technical Information Service \\ 5285 Port Royal Road \\ Springfield, VA 22161 \\ Telephone 703-605-6000 (1-800-553-6847) \\ TDD 703-487-4639 \\ Fax 703-605-6900 \\ E-mail info@ntis.fedworld.gov \\ Web site http://www.ntis.gov/support/ordernowabout.htm
}

Reports are available to DOE employees, DOE contractors, Energy Technology Data Exchange (ETDE) representatives, and International Nuclear Information System (INIS)

representatives from the following source.

Office of Scientific and Technical Information

P.O. Box 62

Oak Ridge, TN 37831

Telephone 865-576-8401

Fax 865-576-5728

E-mail reports@adonis.osti.gov

Web site http://www.osti.gov/contact.html

This report was prepared as an account of work sponsored by an agency of the United States Government. Neither the United States Government nor any agency thereof, nor any of their employees, makes any warranty, express or implied, or assumes any legal liability or responsibility for the accuracy, completeness, or usefulness of any information, apparatus, product, or process disclosed, or represents that its use would not infringe privately owned rights. Reference herein to any specific commercial product, process, or service by trade name, trademark, manufacturer, or otherwise, does not necessarily constitute or imply its endorsement, recommendation, or favoring by the United States Government or any agency thereof. The views and opinions of authors expressed herein do not necessarily state or reflect those of the United States Government or any agency thereof. 
Materials Science and Technology Division

Assessment of End-of-Life Behavior of the Surface Modification to Improve Cavitation-Erosion Resistance in the Mercury Target at the Spallation Neutron Source

S. J. Pawel

Date Published: June 2007

Prepared for the

U.S. Department of Energy

Spallation Neutron Source

Prepared by

OAK RIDGE NATIONAL LABORATORY

Oak Ridge, Tennessee 37831-6285

managed by

UT-Battelle, LLC

for the

U.S. DEPARTMENT OF ENERGY

under contract DE-AC05-00OR22725 



\section{CONTENTS}

Page

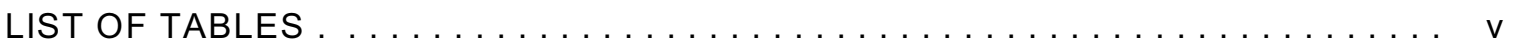

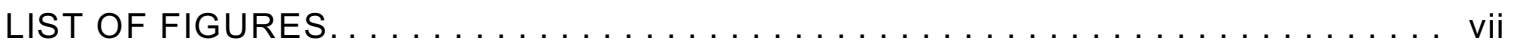

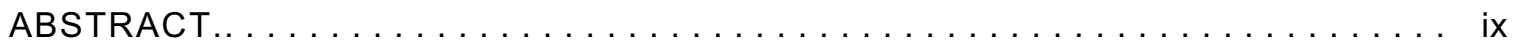

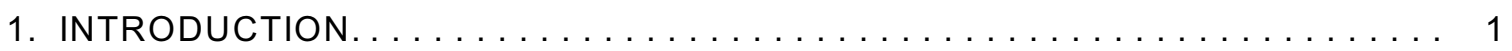

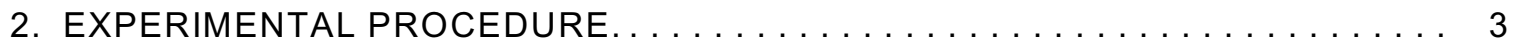

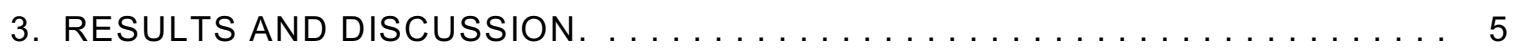

$3.1316 \mathrm{LN}$ Stainless Steel with Annealed Substrate ... . . . . . . . . . 5

$3.2316 \mathrm{LN}$ Stainless Steel with $50 \%$ Cold-Worked Substrate ... . . . . . . . 24

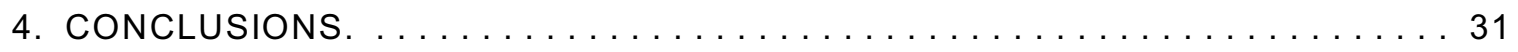

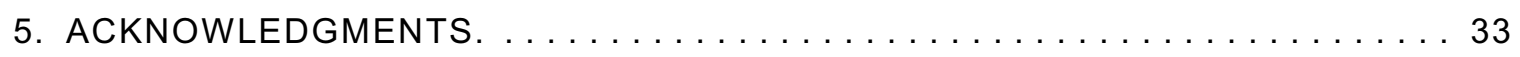

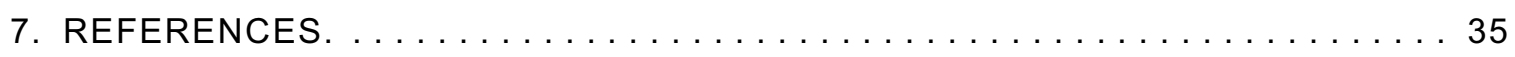





\section{LIST OF TABLES}

Table

Page

1. Composition of master heat of $316 \mathrm{LN}$ stainless steel (Jessop

Steel heat number 18474 ) from the certified mill report . . . . . . . . . . . 3 



\section{LIST OF FIGURES}

Figure

Page

1. Weight loss as a function of sonication time in $\mathrm{Hg}$ at $25-27^{\circ} \mathrm{C}$ for annealed $316 \mathrm{LN}$ specimens that received the

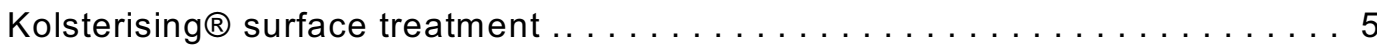

2. Weight loss as a function of time for two of the annealed

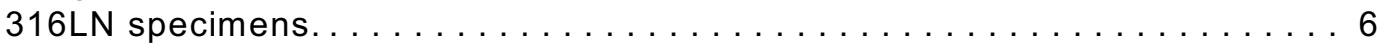

3. Representative cross-section of the annealed/Kolsterised $\AA$ specimen "b" following sonication in mercury for $18 \mathrm{~h}$.

4. Weight loss as a function of sonication time in mercury at $5-27^{\circ} \mathrm{C}$ for specimen "a" (annealed $316 \mathrm{LN}$ with a Kolsterised $\AA$

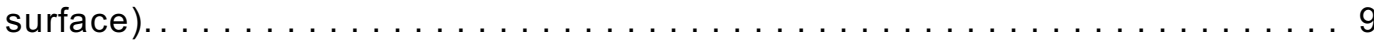

5. Test face of specimen "a" (annealed $316 \mathrm{LN}$ specimen) following Kolsterising ${ }^{\circledR}$ and $20 \mathrm{~h}$ sonication in mercury. . . . . . . . . . . . 10

6. Test face of specimen "a" (annealed $316 \mathrm{LN}$ specimen) following

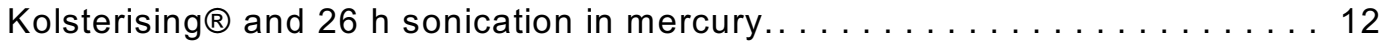

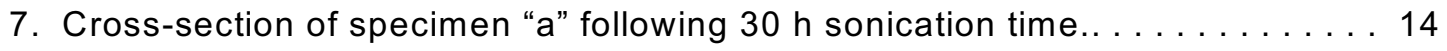

8. Photographs of the test surface of the annealed-plus-Kolsterised $®$ specimen "d" following the indicated sonication times . . . . . . . . . . 15

9. Etched cross-section of the test surface of specimen "d" following $29 \mathrm{~h}$ sonication in mercury at ambient temperature.

10. Cross-section of a pit that has breached the remaining K-layer of

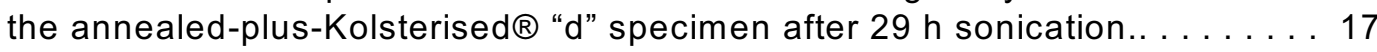

11. Raised lip at the edge of a pit on the annealed-plus-Kolsterised $₫$

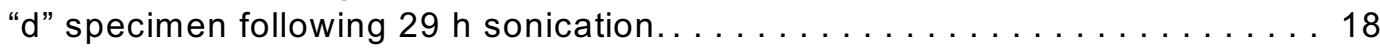

12. Small crack at the interface between the remaining K-layer and the annealed substrate on the "d" specimen following $29 \mathrm{~h}$ sonication. . . . . . 18

13. Crack/pit within the remaining K-layer on the annealed-plus-Kolsterised $₫$ "d" specimen following $29 \mathrm{~h}$ sonication. . . . . . . . . . . . . . . . 19

14. Pit contained within the remaining K-layer on the annealed-plusKolsterised $₫$ "d" specimen following 29 h sonication. . . . . . . . . . . . . . 20 
15. Annealed-plus-Kolsterised $\circledast$ specimen "c" following 24-, 36-, And 42-h of sonication in mercury, respectively, clockwise

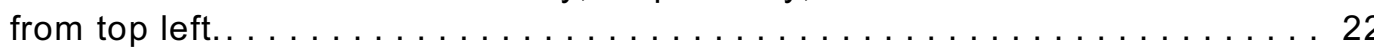

16. Etched cross-section of annealed-plus-Kolsterised $₫$ specimen

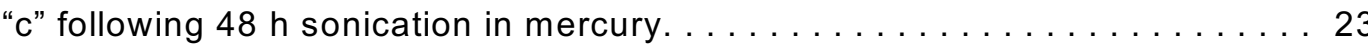

17. Weight loss as a function of sonication time for specimens of $50 \%$ cold-worked $316 \mathrm{LN}$ that received the standard

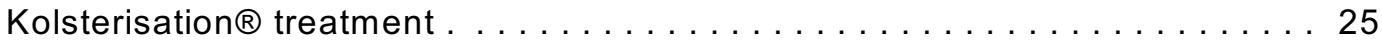

18. Test surface of Kolsterised $®$ specimens with a cold-worked substrate exposed to sonication in mercury for $27 \mathrm{~h}, 33 \mathrm{~h}$, and

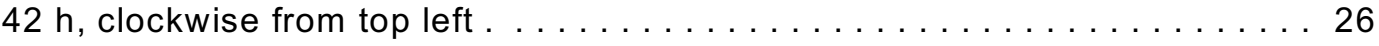

19. Etched cross-section of cold-worked and Kolsterised® specimen

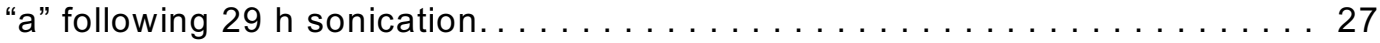

20. Etched cross-section of cold-worked and Kolsterised $\circledast$ specimen

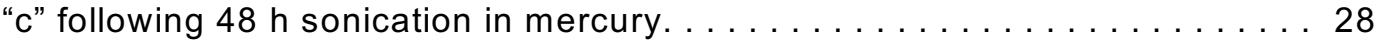

21. Weight loss as a function of sonication time for annealed/Kolsterised $\circledast$ specimen "c" and cold-worked/Kolsterised $₫$ specimen "c".. . . . . . . . . . . . 30 


\begin{abstract}
The cavitation-erosion resistance of the Kolsterised $®$ layer on annealed or cold-worked substrates of $316 \mathrm{LN}$ stainless steel has been examined in mercury using a vibratory horn technique and extended exposure periods intended to expose "end-of-life" performance characteristics. The Kolsterised $₫$ layer tends to remain protective - as evidenced by modest steady-state weight loss and surface roughness increases, only isolated pitting, and limited wetting by mercury - until the protective layer has been thinned by general erosion to about $15-20 \mu \mathrm{m}$. Prior to that amount of erosion, the cavitation-erosion resistance of both types of specimens appears defined by the properties of the protective layer. However, after thinning to such a degree, initial breakdown of the protective layer is characterized by increases in both the surface roughness and the number/depth of individual pits across the surface at a rate that is strongly dependent on the substrate condition, with annealed substrates significantly more prone to damage. However, even as the protective properties of the Kolsterised ${ }^{\circledR}$ layer decrese, both weight change and profile development as a function of sonication time suggest a gradual reversion to cavitation-erosion behavior similar to that of untreated substrates.
\end{abstract}





\section{INTRODUCTION}

One of the strategies to mitigate cavitation-erosion damage in the containment vessel for the mercury target at the Oak Ridge National Laboratory's Spallation Neutron Source (SNS) includes surface treatment of the $316 \mathrm{LN}$ austenitic stainless steel construction material. The selected surface treatment, a proprietary low-temperature carburizing treatment termed Kolsterising ${ }^{\circledR}$ (trademark of the Bodycote Company, Apeldoorn, Netherlands), diffuses carbon into the near-surface material to levels well in excess of the equilibrium solid solubility. Because it is a low temperature treatment, however, the carbon tends to remain in solid solution (in a super-saturated condition rather than forming carbide precipitates) thus providing substantial hardening of the surface via solid solution strengthening as well as strain hardening. ${ }^{1}$

Previous studies of the cavitation-erosion resistance of type $316 \mathrm{LN}$ stainless steel in mercury using a vibratory horn ${ }^{2}$ indicated a very substantial improvement resulting from the Kolsterising ${ }^{\circledR}$ process. Compared to fully annealed material with no surface treatment, incorporation of the standard Kolsterising ${ }^{\circledR}$ process decreased weight loss as a function of sonication time after modest-duration exposures by a factor of 15 or more and, with only very localized exceptions, also eliminated pitting/cratering of the surface common to the annealed material. ${ }^{2}$ The cavitation-erosion resistance of $50 \%$ cold-worked $316 \mathrm{LN}$ was observed to be substantially superior to that of annealed $316 \mathrm{LN}$ in mercury ${ }^{3}$ but, following Kolsterisation $\circledast$ of the surface, the annealed and $50 \%$ cold-worked specimens yielded essentially indistinguishable weight loss results following brief sonication exposures in mercury. ${ }^{2}$

While dramatic improvement in cavitation-erosion resistance as a result of the surface treatment has been demonstrated for $316 \mathrm{LN}$, the lifetime of the protective layer is not expected to be infinite. Eventually, general wastage - or perhaps another end-of-life limitation - is anticipated to compromise or eliminate the protective quality of the hardened layer on the specimen surface. In the experiments reported here, sonication times for Kolsterised $₫$ specimens of $316 \mathrm{LN}$ - with substrates in both the annealed and $50 \%$ cold worked conditions - were extended substantially from previous work to examine "end-of-life" characteristics and the protective (or not) qualities of the surface layer. In particular, determination of the relative rate of reversion to untreated substrate performance characteristics - whether sudden or gradual - was of interest. 



\section{EXPERIMENTAL PROCEDURE}

Test specimens for cavitation-erosion testing were fabricated from type 316LN stainless steel of the composition reported in Table 1. This is the same heat of material used in previous investigations in this series for the SNS target development effort. ${ }^{2-5}$ Specimens were machined from either mill-annealed material (test surface hardness 95-100 DPH or $\mathrm{R}_{\mathrm{b}}$ 55-60) or plate that had been reduced $50 \%$ by cold working (test surface hardness 320-340 DPH or $\mathrm{R}_{c}$ 30-35). Details of the test button size/shape have been described previously. ${ }^{3}$ Following machining, the test specimens received the Kolsterising ${ }^{\circledR}$ treatment at the vendor's facility. Because the specimens used for this investigation were Kolsterised $₫$ in different process batches over a total time of about two years, it cannot be said that the specimens received precisely identical surface treatments. However, the initial thickness of the Kolsterised $®$ layer of material - also termed K-layer in this report - was measured via post-test metallographic analysis of the cross-section of regions on each specimen that were not exposed to sonication conditions (e.g., sides and shank) during testing. In each case, the initial K-layer thickness was found to be in the $32-40 \mu \mathrm{m}$ range (representative hardness profile given in [1] $]^{1}$ for the $33 \mu \mathrm{m}$ thickness), and cavitation-erosion data associated with each K-layer thickness is reported in the next section.

Table 1. Composition of master heat of $316 \mathrm{LN}$ stainless steel (Jessop Steel heat number 18474) from the certified mill report.

\begin{tabular}{cccc}
\hline Elements & Wt \% & Elements & Wt $\%$ \\
\hline C & 0.009 & $\mathrm{Cr}$ & 16.31 \\
$\mathrm{Mn}$ & 1.75 & $\mathrm{Mo}$ & 2.07 \\
$\mathrm{P}$ & 0.029 & $\mathrm{Co}$ & 0.16 \\
$\mathrm{~S}$ & 0.002 & $\mathrm{Cu}$ & 0.23 \\
$\mathrm{Si}$ & 0.39 & $\mathrm{~N}$ & 0.11 \\
$\mathrm{Ni}$ & 10.2 & $\mathrm{Fe}$ & balance
\end{tabular}

Cavitation-erosion tests were performed using a titanium vibratory horn and the general test methodology described in ASTM G-32. ${ }^{6}$ Each test button had a surface area of $180 \mathrm{~mm}^{2}$ exposed to cavitation conditions and was attached to the horn via a 
threaded shank. In all cases, the horn tip oscillated at a fixed frequency of $20 \mathrm{kHz}$ and was set to generate a peak-to-peak vibrational amplitude of $25 \mu \mathrm{m}$. All tests were conducted in a jacketed stainless steel container (about $10 \mathrm{~cm}$ inside diameter), which permitted temperature control of the mercury via circulation of a water/glycol mixture from a constant temperature bath. The mercury temperature was monitored in the test bath and was maintained at $25-27^{\circ} \mathrm{C}$ for all tests. The test specimen surface was immersed $2.5 \mathrm{~cm}$ below the surface of the mercury (total pool depth about $11 \mathrm{~cm}$ ) in the center of the container for all tests. Approximately one liter of high purity mercury was contained within the jacketed vessel and the same mercury was used for all tests. Periodically, cheesecloth was used to skim the mercury surface and remove floating oxide and/or test debris.

Following exposure, test specimens were ultrasonically cleaned sequentially in (1) an aqueous solution containing thiosulfates and other dissolved sulfur species to chemically bind residual mercury, (2) distilled water, and (3) acetone, followed by forced air drying in each case. Specimens were then weighed and examined with an optical microscope to assess the average cavitation-erosion surface profile and to assess pitting/cratering. The profile determination was performed with the calibrated fine focus feature of the optical microscope. Each division on the fine focus knob corresponds to a one-micron vertical movement of the microscope stage, so by sequentially focusing first on the relative high point and then on the low point within a field of view, the depth of surface relief can be estimated. Typically, the average profile, or nominal surface roughness, was determined from measurements at $400 x$ on seven random but regularly spaced locations across the test surface, with observations of areas of profile significantly different than the average noted as appropriate. Selected specimens were also sectioned for metallographic assessment of the profile and microstructural effects, and microhardness (Vickers) profiles across the surface layer into the substrate were obtained on a limited number of the polished cross-sections. 


\section{RESULTS AND DISCUSSION}

\subsection{LN Stainless Steel with Annealed Substrate}

Figure 1 shows the weight loss data as a function of total sonication time in mercury for the annealed specimens receiving the Kolsterisation $₫$ treatment. There are a total of four specimens represented in this graph. Among these, specimens "a" and " $b$ " had an initial case depth (also termed K-layer in this report) of 32-33 $\mu \mathrm{m}$, while specimens "c" and "d" exhibited an initial K-layer thickness of $40 \mu \mathrm{m}$.

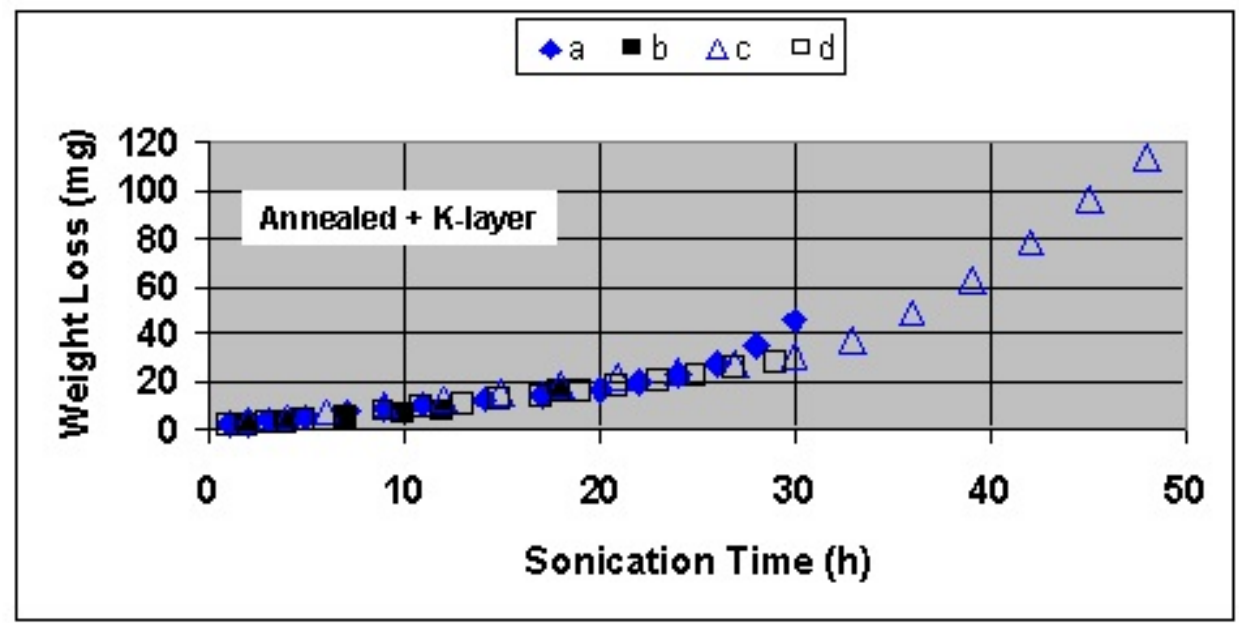

Fig. 1. Weight loss as a function of sonication time in $\mathrm{Hg}$ at 25$27^{\circ} \mathrm{C}$ for annealed $316 \mathrm{LN}$ specimens that received the Kolsterising ${ }^{\circledR}$ surface treatment. Specimens "a" and "b" exhibited an initial K-layer about $33 \mu \mathrm{m}$ thick, while specimens "c" and "d" had an initial K-layer thickness of about $40 \mu \mathrm{m}$. Note that there is sufficiently little scatter in the data that many of the data points are individually indistinguishable.

Figure 1 suggests that the Kolsterisation $®$ process results in a relatively consistent surface condition in that there is remarkably similar weight loss and resistance to pitting among a group of specimens treated in three different processes over a span of almost two years. The steady-state weight loss rate observed for each specimen - independent of initial K-layer thickness within the limited range examined - was essentially constant at $0.7-0.8 \mathrm{mg} / \mathrm{h}$ over a sonication period of up to $25 \mathrm{~h}$ or more. The weight loss rate observed previously for identical annealed specimens without the Kolsterisation $®$ treatment was also constant over extended periods but in the range of $12-13 \mathrm{mg} / \mathrm{h}^{2,3}$ In 
light of this comparison, it seems reasonable to conclude that the surface treatment provides significant protection of the annealed surface for a period extending to $25 \mathrm{~h}$ or more (corresponds to almost $2 \times 10^{9}$ cavitation cycles on the vibratory horn). Note that, even at the longest exposure time indicated in Fig. 1 (48 h), the weight loss rate for this annealed specimen has increased to only about $5.9 \mathrm{mg} / \mathrm{h}$, or about half of the "unprotected" value for annealed 316LN. Details of the end-of-life qualities of the protective layer will be developed more fully in subsequent paragraphs.

Figure 2 is a segment of the data in Fig. 1 that has been re-scaled for clarity. It shows the weight loss data as a function of sonication time for the first two K-layer specimens with an annealed substrate ("a" and "b") evaluated in this investigation. Aside from a slightly accelerated weight loss very early in the exposure for specimens "a," the weight loss as a function of time for these two specimens was nearly identical over a period of about $15 \mathrm{~h}$. Following $15 \mathrm{~h}$ sonication, both specimens exhibited a nominal surface profile on the order of $5 \mu \mathrm{m}$ and only very limited/isolated pitting perhaps 8-12 roughly hemispherical pits in the range of 50-100 $\mu \mathrm{m}$ deep. In addition, immediately following sonication, the specimen test surfaces shed essentially all mercury within seconds of removal from the mercury bath, indicating very limited wetting had developed.

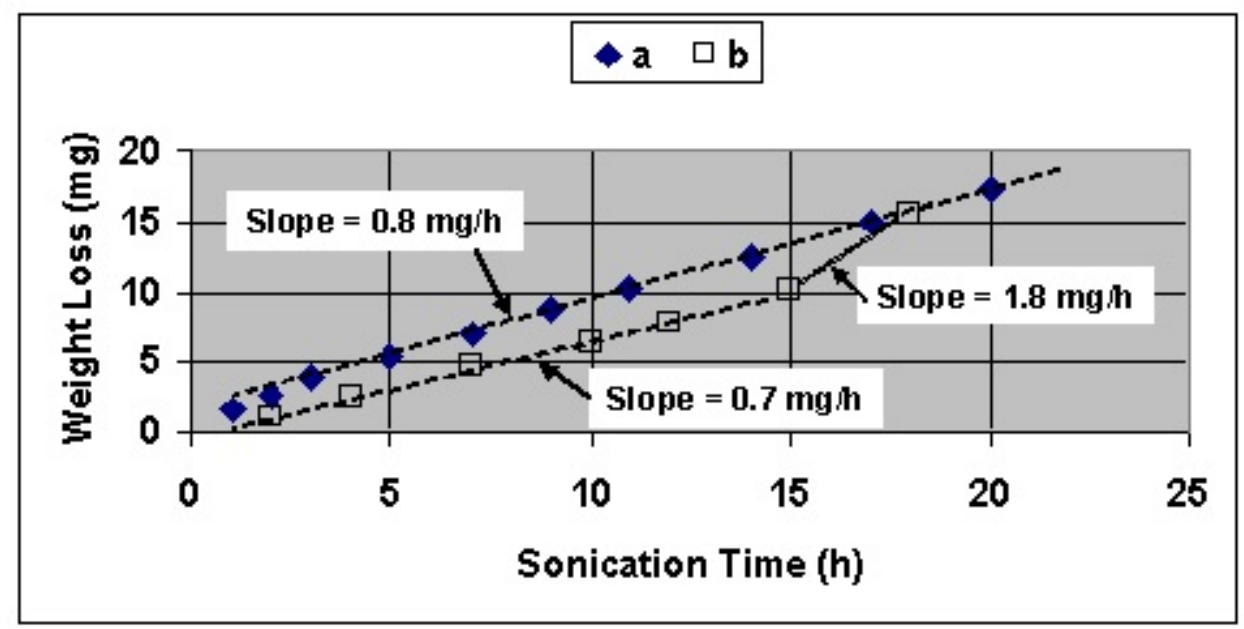

Fig. 2. Weight loss as a function of time for two of the annealed 316 LN specimens. Note the change in slope in the data for specimen "b" between 15 and $18 \mathrm{~h}$ sonication time. 
However, a change in the slope of the weight loss curve between 15 and $18 \mathrm{~h}$ exposure for annealed specimen "b" signaled the potential onset of a change in the protective quality of the Kolsterised $\circledast$ layer. As a result, specimen "b" was sacrificed for metallography after $18 \mathrm{~h}$ of sonication; Fig. 3 shows a representative cross-section of the specimen following light etching to reveal the structure. The band of material across the top of the specimen that appears relatively featureless is the Kolsterised $₫$ layer - in this view, the layer has a relatively uniform thickness of about $20 \mu \mathrm{m}$. Heavier etching would reveal that the Kolsterised $\circledast$ layer actually has a structure continuous with the substrate features, but one aspect of Kolsterising ${ }^{\circledR}$ is that it tends to impart slightly increased corrosion resistance to many environments, and that feature was utilized here to highlight the thickness of the remaining layer with very light etching. The specimen surface, as represented by the view in Fig. 3, reveals a maximum surface profile of less than $10 \mu \mathrm{m}$ between the high and low spots and an average roughness of less than $5 \mu \mathrm{m}$.

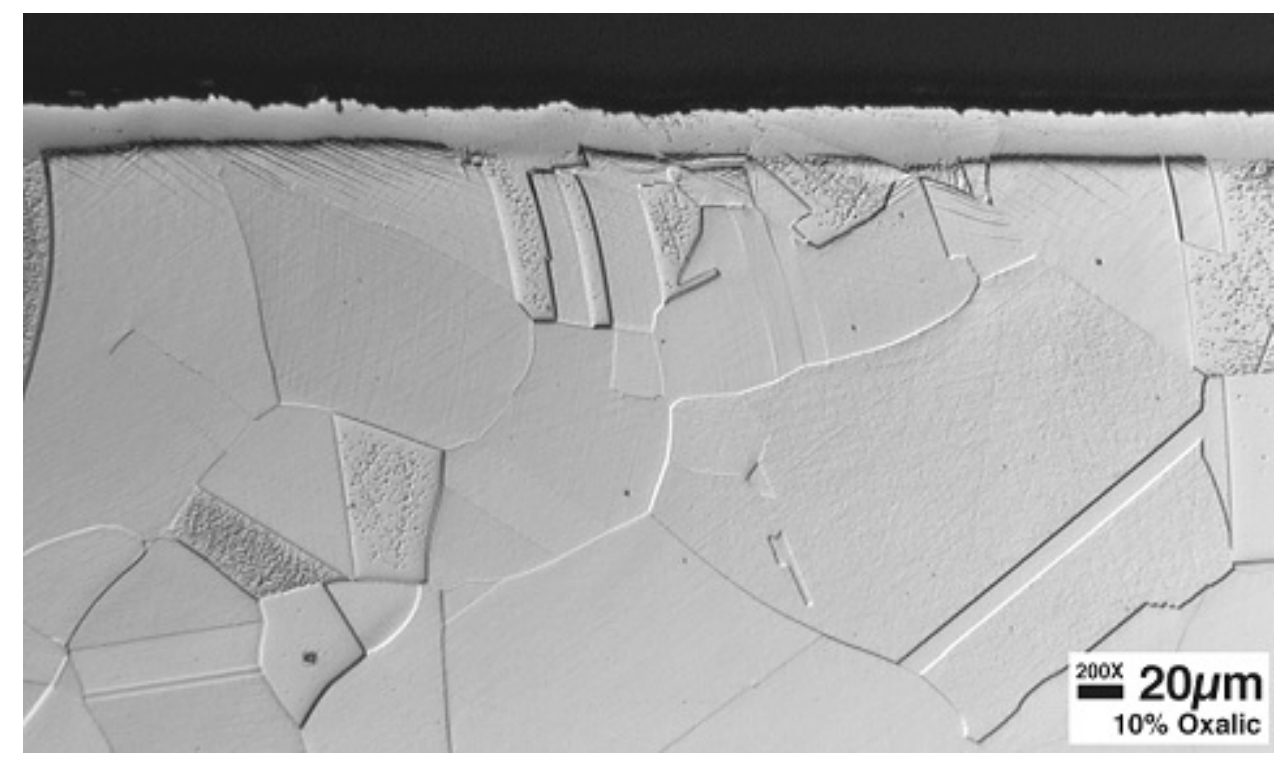

Fig. 3. Representative cross-section of the annealed/Kolsterised $\circledast$ specimen " $b$ " following sonication in mercury for $18 \mathrm{~h}$. The mounting epoxy (appears black) is at the top of the photograph and the test surface exposed to mercury is immediately adjacent to the mounting epoxy. The Kolsterised $\otimes$ layer is the essentially featureless band roughly parallel to the test surface that is about $20 \mu \mathrm{m}$ thick. 
From views of parts of the specimen unexposed to sonication conditions (for example, the "backside" of the test button), it is clear that the original Kolsterised $®$ layer was about $32 \mu \mathrm{m}$ thick on average. Based on the metallographic examination like that shown in Fig. 3, specimen "b" exhibited a remarkably uniform thinning of the Kolsterised layer from the original value of $32 \mu \mathrm{m}$ to an average of $20 \mu \mathrm{m}$ in the $18 \mathrm{~h}$ exposure. Based on uniform weight loss over the same period, this degree of thinning corresponds to about $0.7 \mu \mathrm{m} / \mathrm{h}$. (For comparison, a value of about $2.0 \mu \mathrm{m} / \mathrm{h}$ was previously observed for thinning of plasma-nitrided layers applied to Kolsterised layers on $316 \mathrm{LN}$ specimens. $)^{5}$ Using the density of the $316 \mathrm{LN}$ material $\left(8.0 \mathrm{~g} / \mathrm{cm}^{3}\right)$ and the total test surface area $\left(1.8 \mathrm{~cm}^{2}\right)$, note that the total mass associated with uniform removal of about $12 \mu \mathrm{m}$ of K-layer thickness $(\sim 17.3 \mathrm{mg})$ corresponds almost exactly with the total weight loss $(17.5 \mathrm{mg}$ ) experienced by the specimen in $18 \mathrm{~h}$ (see Fig. 3 ). This result indicates that mass loss to this point in the sonication exposure has been almost exclusively due to uniform thinning (general erosion and micro-pitting) of the protective layer of carburized material and very little mass loss has occurred due to localized pitting, which is readily confirmed by observation of the test surface prior to metallographic examination.

Also in Fig. 3, the substrate material immediately adjacent to the Kolsterised $\circledast$ layer (just beneath the layer in the photograph) reveals a high density of slip lines. The slip lines appear as clusters of short parallel indications within the grains of the substrate. Slip lines like these are not present within the grains of fully annealed material (the starting stock to fabricate these specimens) but are present beneath all of the treated surfaces of each specimen and thus it is likely the slip lines result from the high localized lattice strain - in effect, a modest amount of cold-work - associated with the diffusion of extreme amounts of carbon into a restricted volume of material and the steep composition gradient that results between the fully carburized layer and the substrate material. The presence of the slip lines beneath the layer confirms strength/hardness benefits associated with the Kolsterised $®$ layer penetrate further into the specimen than the obvious "boundaries" of the physical layer itself. [Note that the slip lines are rarely seen in all grains of the substrate - particular grain orientations and etching conditions make these features more or less visible.]

Aside from thinning of the K-layer to about $20 \mu \mathrm{m}$, however, no features such as breaching/spalling of the K-layer were observed on the specimen "b" test surface to suggest a reason for the relatively abrupt change in slope associated with weight loss as a function of sonication time. Consequently, data for the equivalent annealed-plus- 
olsterised $\circledast$ specimen "a" was extended until a much more significant/persistent change in slope was observed at $30 \mathrm{~h}$ total exposure. Figure 4 incorporates the extended exposure time data for specimen "a" as a stand-alone curve.

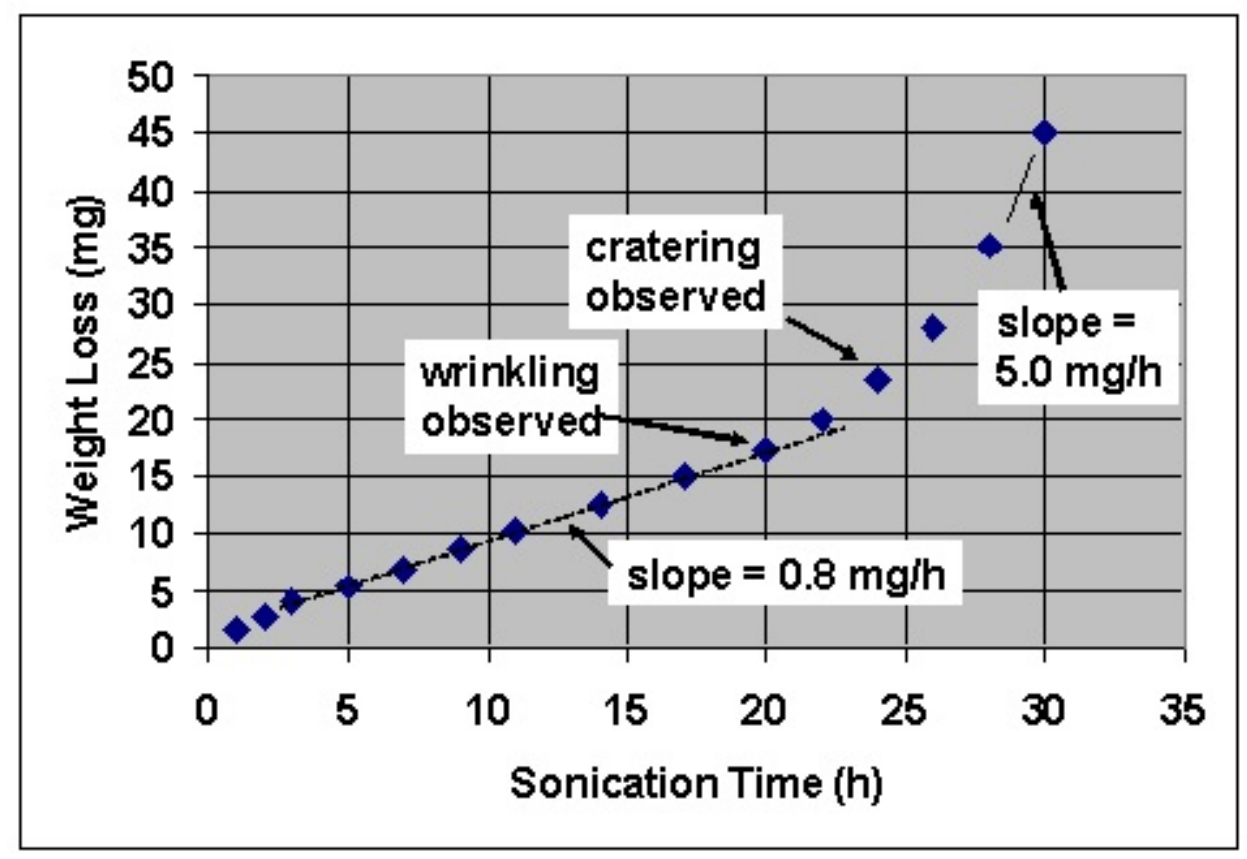

Fig. 4. Weight loss as a function of sonication time in mercury at $25-27^{\circ} \mathrm{C}$ for specimen "a" (annealed $316 \mathrm{LN}$ with a Kolsterised ${ }^{\circledR}$ surface).

Corresponding surface profile data for the weight loss curve in Fig. 4 revealed that the test surface roughness remained at about $3 \mu \mathrm{m}$ or less until about $9 \mathrm{~h}$ exposure, and the surface roughness had increased to only about $5 \mu \mathrm{m}$ following $14 \mathrm{~h}$ exposure. Following $20 \mathrm{~h}$ of exposure for specimen "a," the average surface profile was measured with the optical microscope to be $19 \mu \mathrm{m}$. Figure 5 shows the test surface of annealed-plusKolsterised $\circledast$ specimen "a" following $20 \mathrm{~h}$ exposure - it includes about 10 pits large enough to easily detect at this modest magnification and some "wrinkling" of the surface - a general loss of smoothness that seems to be a precursor to the initiation of higher weight loss rates. This "wrinkling" of the specimen surface is simply the macroscopic manifestation of the increase in surface roughness/profile of the specimen - in effect, the onset of failure in the K-layer - and as a generality among these test specimens, it becomes detectable at low magnification (e.g., 10x) at 10-12 $\mu \mathrm{m}$ roughness. Among the 
pits observed on the specimen surface following $20 \mathrm{~h}$ sonication, only eight were recorded having depths greater than $75 \mu \mathrm{m}$, with the deepest being the somewhat elongated pit near the right edge of the specimen $(215 \mu \mathrm{m})$. Also, following $20 \mathrm{~h}$ exposure, increased post-test wetting of mercury was observed on the test surface, which was apparently related to the development of wrinkled areas on the surface. Nevertheless, the cleaning process remained effective (albeit somewhat slower) for mercury removal.

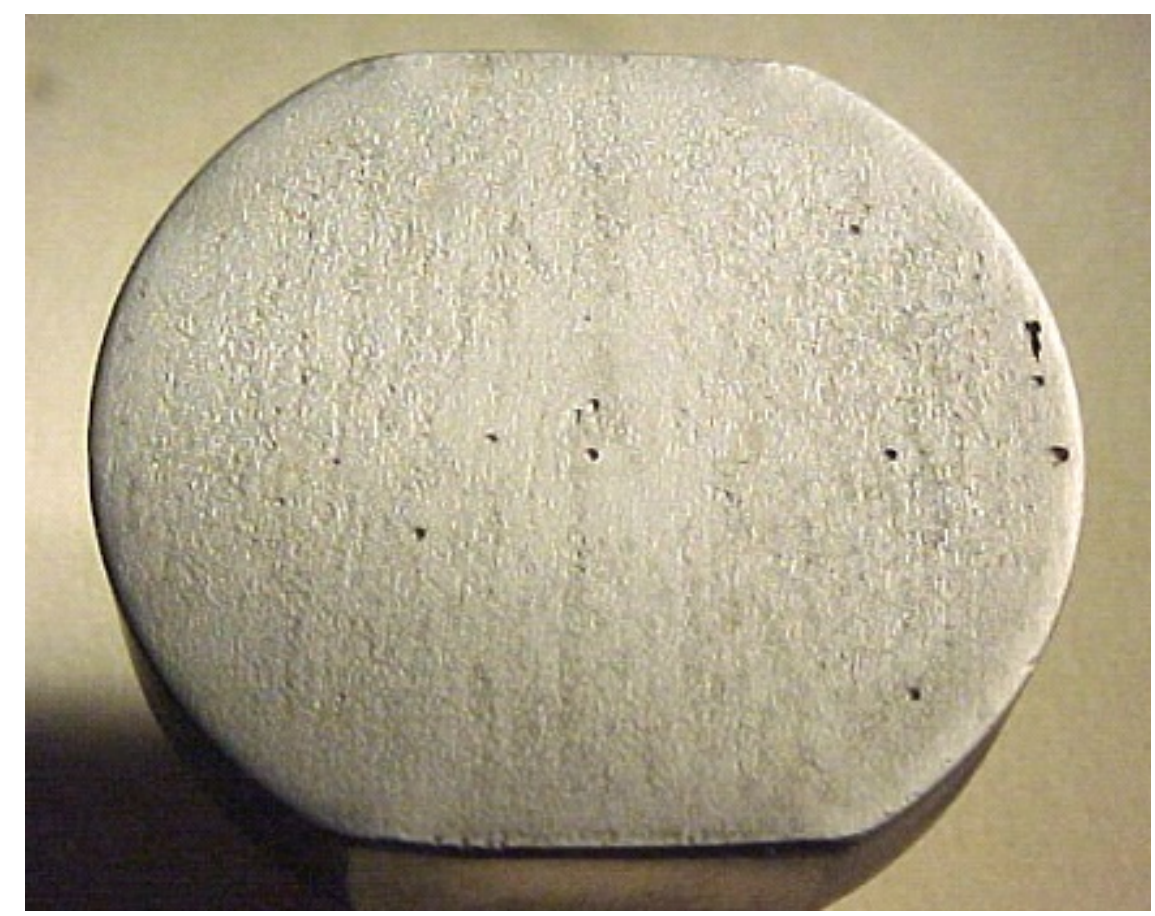

Fig. 5. Test face of specimen "a" (annealed 316LN specimen) following Kolsterising ${ }^{\circledR}$ and $20 \mathrm{~h}$ sonication in mercury. Actual specimen diameter is $16 \mathrm{~mm}$.

Extended exposure steadily increased the nominal surface roughness of specimen "a" while existing pits grew deeper and new pits formed more and more densely on the surface. Interestingly, pits were not regularly observed to increase in diameter as the pits grew deeper. Apparently, the remaining Kolsterised $($ layer (covering areas surrounding the pit) tends to inhibit a pit diameter increase, but at areas where the protective layer has been breached, there is little resistance to the pits becoming deeper at a rate similar to that observed on untreated material. The edges of the pits formed to this point in the exposure generally exhibited a largely flat surface profile (same relative 
elevation and surface roughness as areas remote to any pitting). However, between about 24 and $26 \mathrm{~h}$ exposure, some pits on this specimen began to resemble an impact crater in that the pit rim was no longer an extension of the bulk surface (relatively smooth), but exhibited a raised (above the surrounding profile) rim around the pit. This change in behavior corresponds to enlarged areas where the carburized layer has been breached, and indicates the substantial power/deformation associated with the cavitation process.

Following $26 \mathrm{~h}$ exposure, the slope of the weight loss curve for specimen "a" approximately tripled from the steady state value observed during the initial $20 \mathrm{~h}$ of testing (see Fig. 4), and Fig. 6 records the test face of this specimen following $26 \mathrm{~h}$ sonication. At this point, the nominal surface roughness had increased to about $36 \mu \mathrm{m}-$ independent of the many pits, which also became much more numerous (compare to Fig. 5). Also, note the almost complete absence of relatively smooth (non-wrinkled) areas on the surface. At this point in the exposure, a large fraction (>75\%) of the specimen surface tended to exhibit wetting by mercury for an extended period following testing.

Exposure for annealed-plus-Kolsterised $₫$ specimen "a" was extended to $30 \mathrm{~h}$, at which point the slope of the weight loss curve was a factor of six or more larger than the steady state value recorded for the first $20 \mathrm{~h}$ or so of sonication. [This is still less than half of the weight loss rate for an annealed/untreated $316 \mathrm{LN}$ specimen.] At this point, the general surface roughness had increased to more than $100 \mu \mathrm{m}$ and several pits exceeded $150 \mu \mathrm{m}$ in depth, with the deepest recorded to be $260 \mu \mathrm{m}$. Essentially $100 \%$ post-test wetting was observed for a significant duration, further suggesting that thinning/roughening of the original Kolsterised $®$ layer alters potential intraction with mercury. 


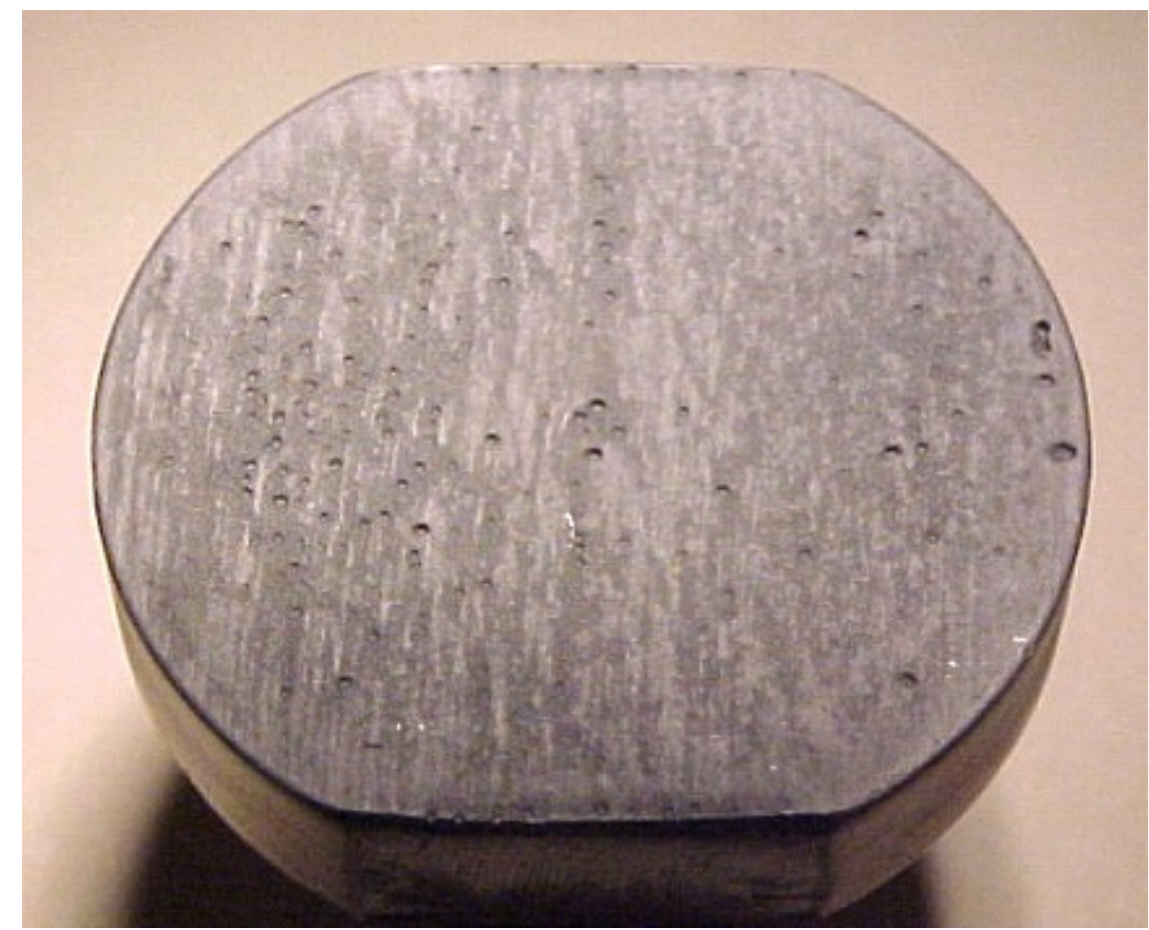

Fig. 6. Test face of specimen "a" (annealed 316LN specimen) following Kolsterising ${ }^{\circledR}$ and $26 \mathrm{~h}$ sonication in mercury. Actual specimen diameter is $16 \mathrm{~mm}$. Compare to Fig. 5.

Following $30 \mathrm{~h}$ sonication, annealed-plus-Kolsterised® specimen "a" was sacrificed for metallographic examination. Figure 7 reveals a test surface cross-section almost devoid of the Kolsterised $₫$ layer. A representative of the last vestige of the Kolsterised $\circledast$ layer in Fig. 7 is the light colored surface material about $15 \mu \mathrm{m}$ thick (original thickness $\sim 32 \mu \mathrm{m}$ ) near the right edge of the top photo Fig. 7. Compared to a loss of about $12 \mu \mathrm{m}$ of K-layer following $18 \mathrm{~h}$ exposure for specimen "b," the loss of K-layer seems to be accelerating locally over the next few hours of exposure as it is absent over large areas altogether at $30 \mathrm{~h}$ exposure, and generally has $15 \mu \mathrm{m}$ or less in areas where it remains on specimen "a" after this exposure period. Figure 7 also reveals a pit without a raised lip, indicating either that this pit was formed by multiple tiny impacts insufficient to produce a raised lip or that the raised edges have been eroded away. In the bottom photo in Fig. 7, slip lines can be seen along the bottom edge of the pit, indicating significant stress/strain deformation associated with the cavitation-erosion process in the annealed substrate material. In addition, at the extreme right edge of the specimen surface in the bottom photo of Fig. 7, the remnants of the Kolsterised $®$ layer are fully 
contiguous/adherent with the surface material. The piece of metallic material that appears near, but slightly removed from, the pit surface at the left is attached to the test face at a point somewhat removed from the view in this particular cross-section. The pits shown in Fig. 7 also represent the consistent observation that the pits formed as a result of vibratory horn exposures in mercury in these experiments often have asymmetrical shapes - in particular, one side of the pit is often very steeply sloped while the other is not - but that undercut of the exposed surface has not been observed by the author on similar specimens in any related work. ${ }^{2-5}$

Annealed-plus-Kolsterised $\circledast$ specimen "d" was also sacrificed for metallography following $29 \mathrm{~h}$ exposure. Specimen " $\mathrm{d}$ " exhibited the first significant deviation from the steady state weight loss rate at 25-27 h exposure (compared to 20-22 $\mathrm{h}$ for specimen "a"). The somewhat superior resistance to cavitation-erosion - increased time to K-layer breakdown - of specimen "d" is most likely a direct result of the greater initial thickness of the K-layer on this specimen, which was near $40 \mu \mathrm{m}$ compared to $32-33 \mu \mathrm{m}$ on specimens "a" and "b." [Note that the ratio of initial layer thickness of 40/32 is essentially identical to the ratio of nominal time to deviation from steady state of $26 / 21$.]

Figure 8 is a series of photographs of the test surface of specimen "d" as the point of deviation from the steady state weight loss rate was approached and exceeded. Following $12 \mathrm{~h}$ sonication, the specimen surface was largely smooth and free of significant pits or surface roughness $(\sim 3 \mu \mathrm{m})$. After $21 \mathrm{~h}$ sonication, isolated pits (only four pits deeper than $100 \mu \mathrm{m}$, deepest was about $225 \mu \mathrm{m}$ ) were observed to be getting deeper at a rate similar to the pits on untreated material, and "wrinkling" of the surface was observed (perhaps initiated at $19 \mathrm{~h}$ exposure but required some low magnification to resolve), generating a nominal surface roughness of about $23 \mu \mathrm{m}$. Following $27 \mathrm{~h}$ sonication, there were many pits $\geq 100 \mu \mathrm{m}$ deep - two pits were greater than $200 \mu \mathrm{m}$ deep - and the nominal surface roughness had increased to $57 \mu \mathrm{m}$. After $29 \mathrm{~h}$ sonication, when a modest but definite change in the weight loss curve became readily detectable, the pitting observed was extensive and the nominal surface roughness had increased to $74 \mu \mathrm{m}$ accompanied by extensive post-test wetting of mercury. 

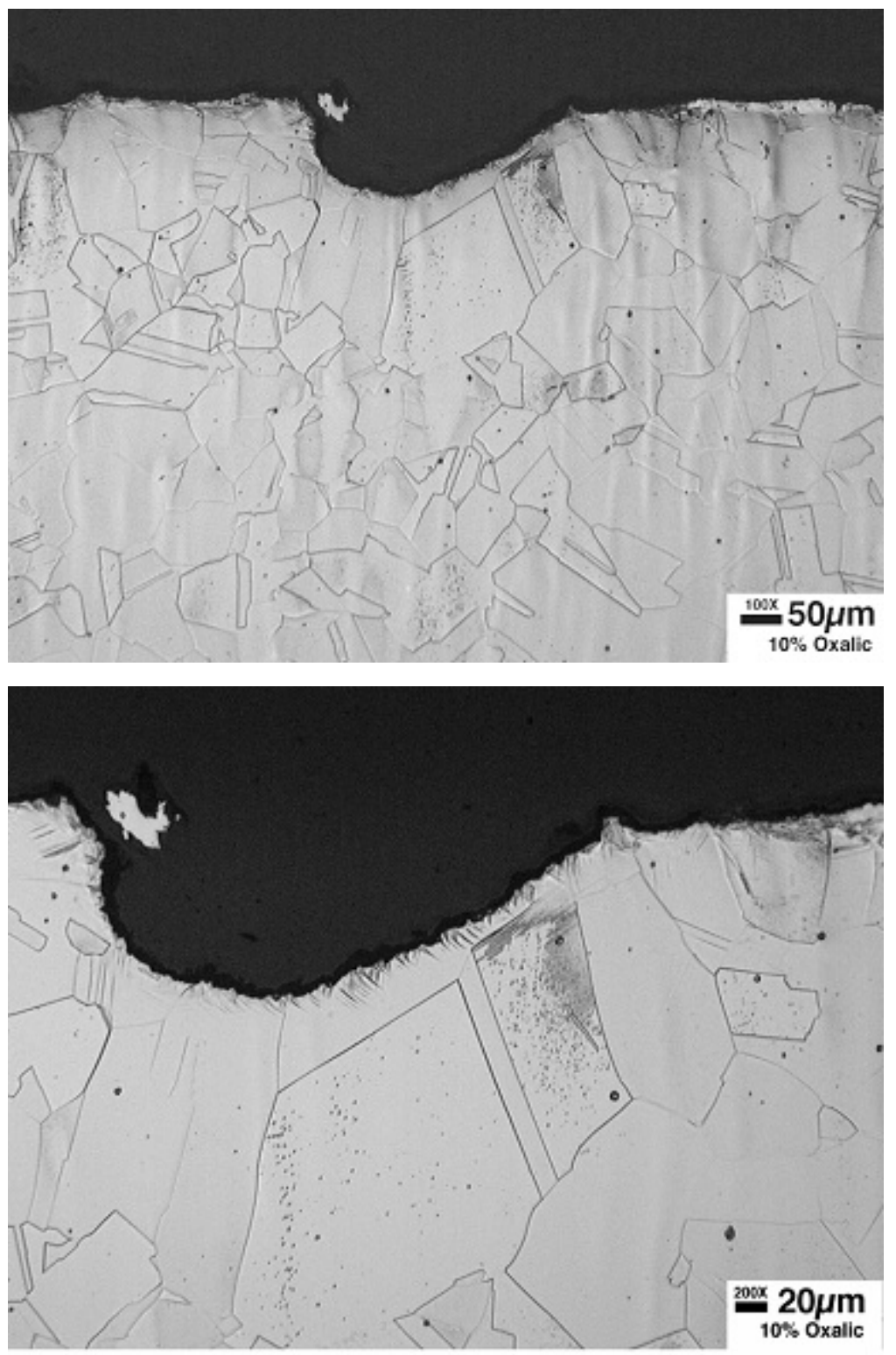

Fig. 7. Cross-section of specimen "a" following $30 \mathrm{~h}$ sonication time. Top photo: Low magnification view showing a pit on an otherwise relatively undisturbed area. Bottom photo: Higher magnification of the same pit showing slip lines at the bottom, indicating deformation of the substrate at this location. 

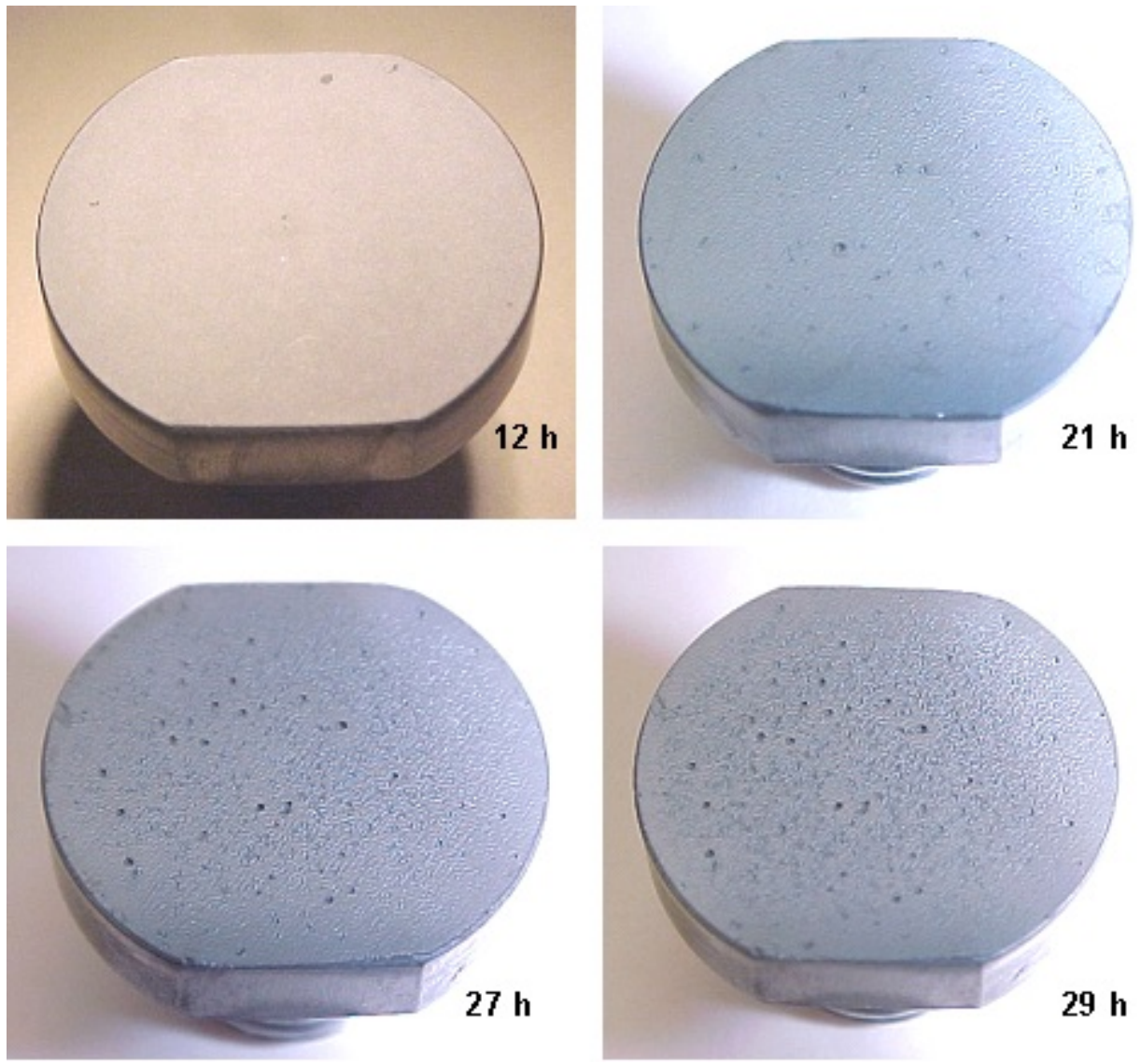

Fig. 8. Photographs of the test surface of the annealed-plusKolsterised $\circledast$ specimen " $d$ " following the indicated sonication times. The surface following $12 \mathrm{~h}$ exposure is essentially smooth and free of pits; however, a few small water stains are visible on the test surface. Wrinkling and pitting of the surface develop rapidly from 21 to 29 hours of exposure.

Figure 9 is a relatively low magnification view of the "d" specimen test surface in cross-section following $29 \mathrm{~h}$ sonication, and it reveals representative modest surface relief and the onset of pitting that has breached the remaining Kolsterised $₫$ layer thickness. Although the thickness of the remaining surface layer is not particularly uniform, the average remaining thickness of $20 \mu \mathrm{m}$ (equates to a loss of $20 \mu \mathrm{m}$ from the initial $40 \mu \mathrm{m}$ thickness) after $29 \mathrm{~h}$ sonication corresponds to a thinning rate of about $0.7 \mu \mathrm{m} / \mathrm{h}$, or essentially identical to the value estimated for the annealed "a" and "b" specimens. Also similar to specimens "a" and "b," the onset of failure in the K-layer (increase in weight loss, initial pitting) seems to have begun with about $20 \mu \mathrm{m} \mathrm{K}$-layer remaining. 


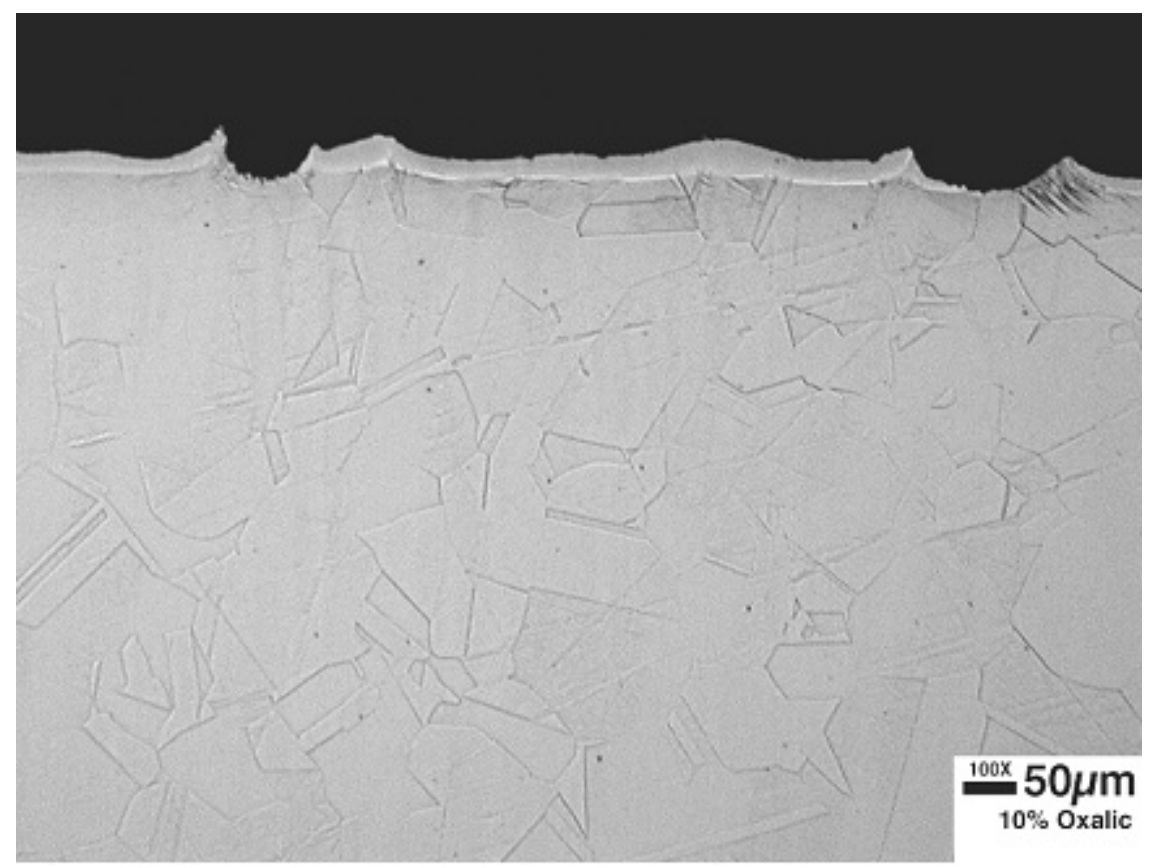

Fig. 9. Etched cross-section of the test surface of specimen " $d$ " following $29 \mathrm{~h}$ sonication in mercury at ambient temperature. Note cavitation craters that have breached the K-layer.

Figures 10-12 are additional cross-section photographs of the initiation of the pitting process on the "d" specimen. Figure 10 shows a $120 \mu \mathrm{m}$ deep pit that has breached the remaining thickness of the Kolsterised $\circledast$ layer. This view reveals several facets of the cavitation-erosion process. Note that the surfaces of the pit itself are rough and irregular (consistent with the type of damage observed in scanning electron microscopy photographs of surfaces cavitated in mercury). ${ }^{2,3}$ Also note that, as before, slip lines in the substrate metal (bottom and sides of the pit) indicate significant deformation is associated with the cavitation-cratering process. Further, note that the Kolsterised $\circledast$ layer itself has been pushed upward by the force of the cavitation-cratering event, as seen best by the raised/curved lip of Kolsterised $®$ material at the surface of the right side of the pit. [As the raised lip becomes more and more pronounced, the author has used the term "crater" to distinguish this feature from a "pit" - the latter term implying the surrounding topography has not been disturbed significantly.] Figure 11 shows a particularly pronounced lip at the edge of the developing crater. At the surface of the left edge of the crater, note the uplifting of the Kolsterised $®$ layer and also the very thin layer 
of substrate material adhering to the underside of the lifted Kolsterised $\circledast$ material. Such behavior demonstrates a special feature of the Kolsterising ${ }^{\circledR}$ process compared to other surface treatments: because it is a diffusion process rather than something discretely applied to the surface, there is no precise interface between the protective layer and substrate and therefore the protective layer tends not to exhibit the shortcomings often associated with poor adhesion between layers. Also note that the Kolsterised $₫$ layer itself has developed modest surface relief (localized wastage and tiny pits/cracks) at this point in the sonication process. Figure 12 exhibits a crack that has formed at the interface of the remaining Kolsterised $®$ material and the substrate metal near the right side of the developing crater.

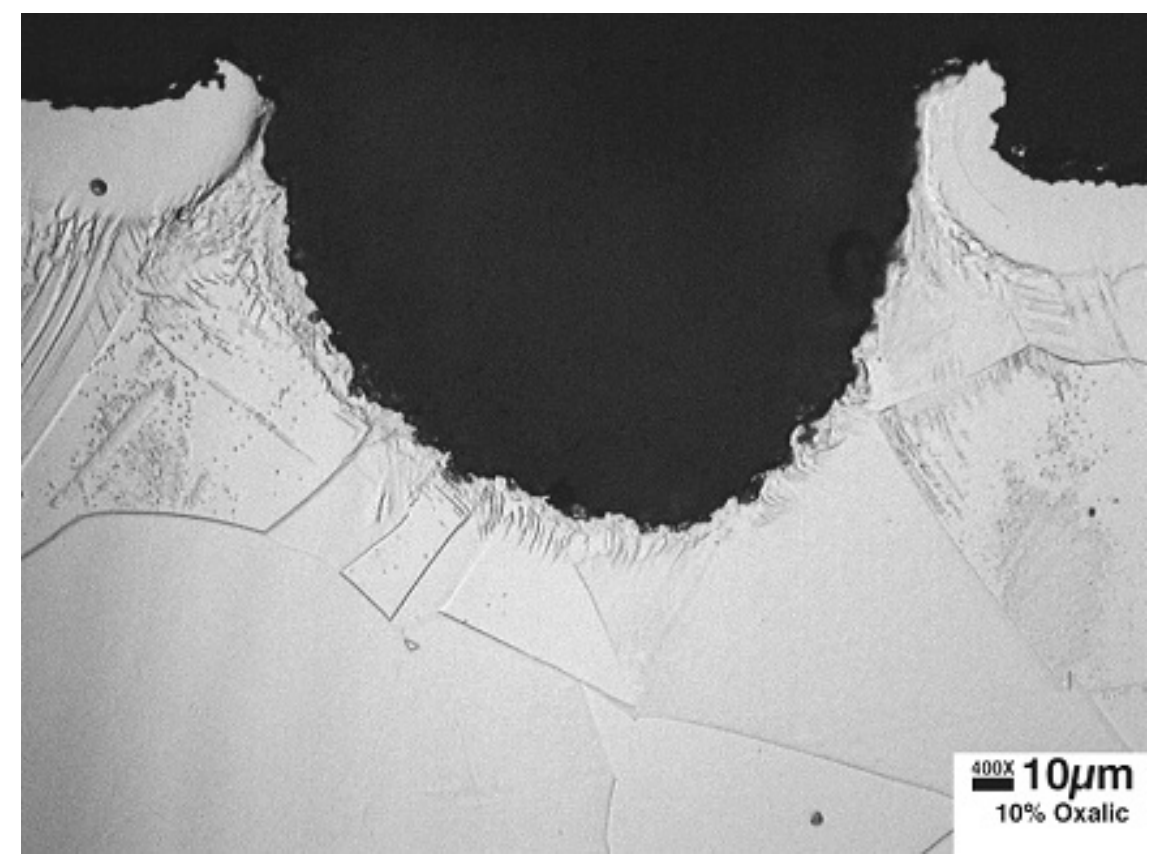

Fig. 10. Cross-section of a pit that has breached the remaining K-layer of the annealed-plus-Kolsterised ${ }^{\circledR}$ " $d$ " specimen after $29 \mathrm{~h}$ sonication. Note the raised lip at the edge of the pit and the slip lines in the annealed material at the bottom of the pit. 


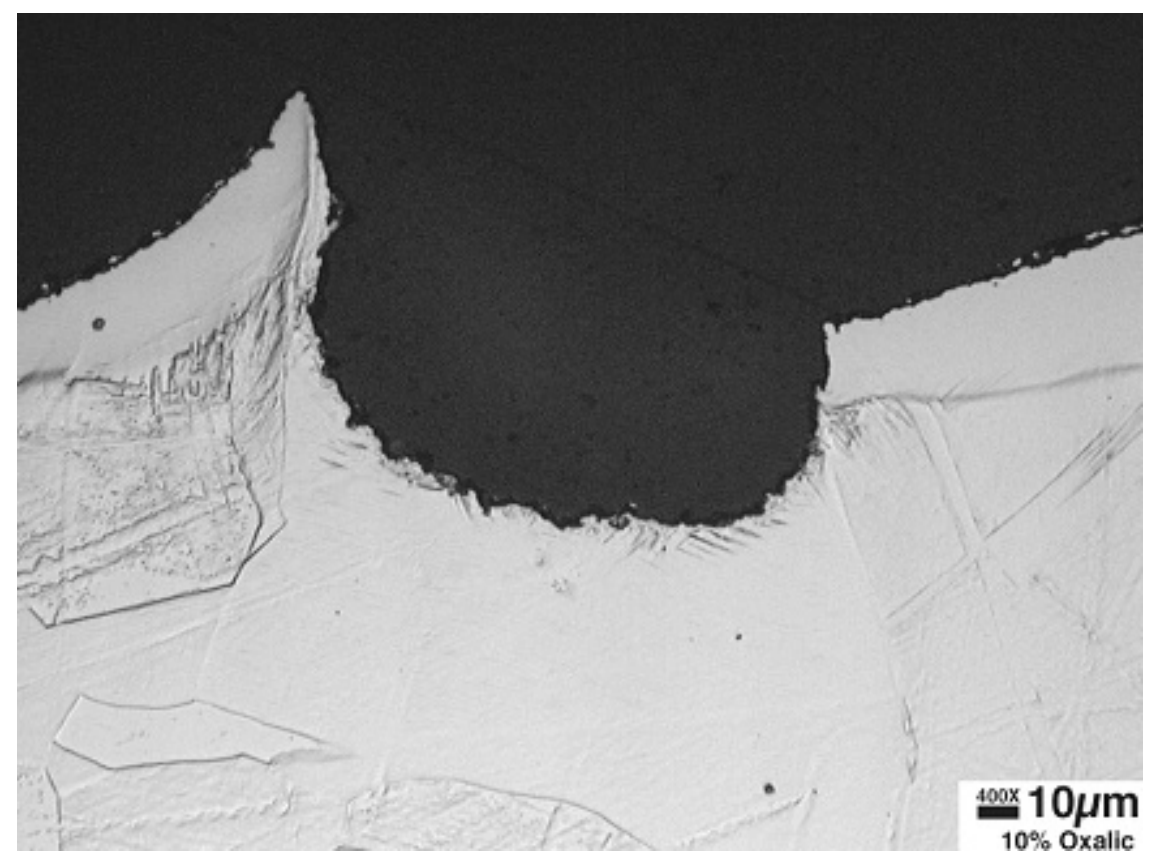

Fig. 11. Raised lip at the edge of a pit on the annealedplus-Kolsterised $®$ " $d$ " specimen following 29 h sonication. Note the adherence of a thin layer of base material beneath the raised K-layer.

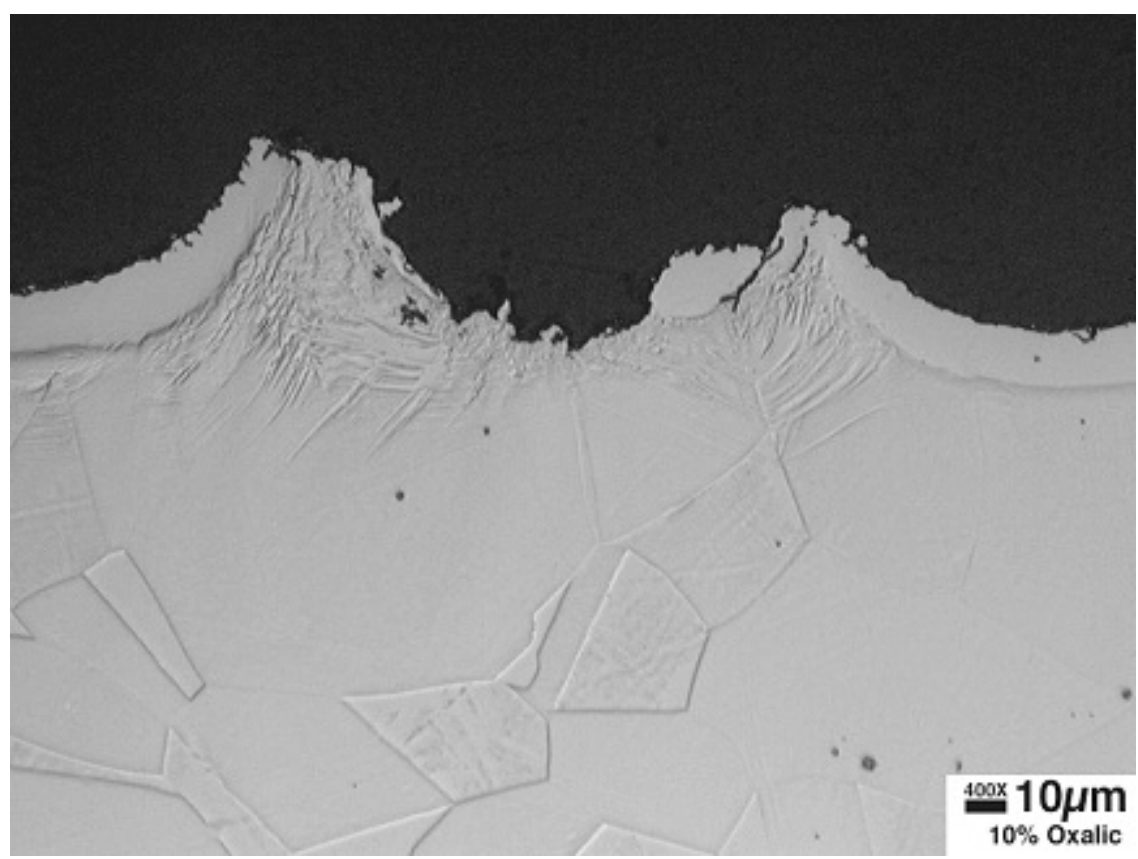

Fig. 12. Small crack at the interface between the remaining $K$-layer and the annealed substrate on the " $d$ " specimen following $29 \mathrm{~h}$ sonication. Note also the roughening of the surface of the remaining $\mathrm{K}$-layer. 
Figures 13 and 14 are somewhat different from the previous views of specimen "d" in that they show the initiation of the pitting process while it is confined within the remaining Kolsterised $\circledast$ layer. Figure 13 reveals what appears to be the initiation of a pit/crack within the remaining Kolsterised $®$ layer. At the place where pitting has initiated in the $\mathrm{K}$-layer, the local thickness is again near the apparent threshold for initial breakdown $(20 \mu \mathrm{m})$. Note particularly at the left edge of the near-breach in the K-layer, localized deformation associated with the cavitation process has uplifted and elongated even the very hard protective layer compared to its original thickness and position. Deformation of the substrate (as indicated by the high concentration of slip lines) appears concentrated in the substrate just beneath the near-breach. Figure 14 shows a more developed pit/crater, but one that is nevertheless fully contained within the Kolsterised ${ }^{\circledR}$ material. It also reveals significant deformation of the Kolsterised $\circledast$ layer itself.

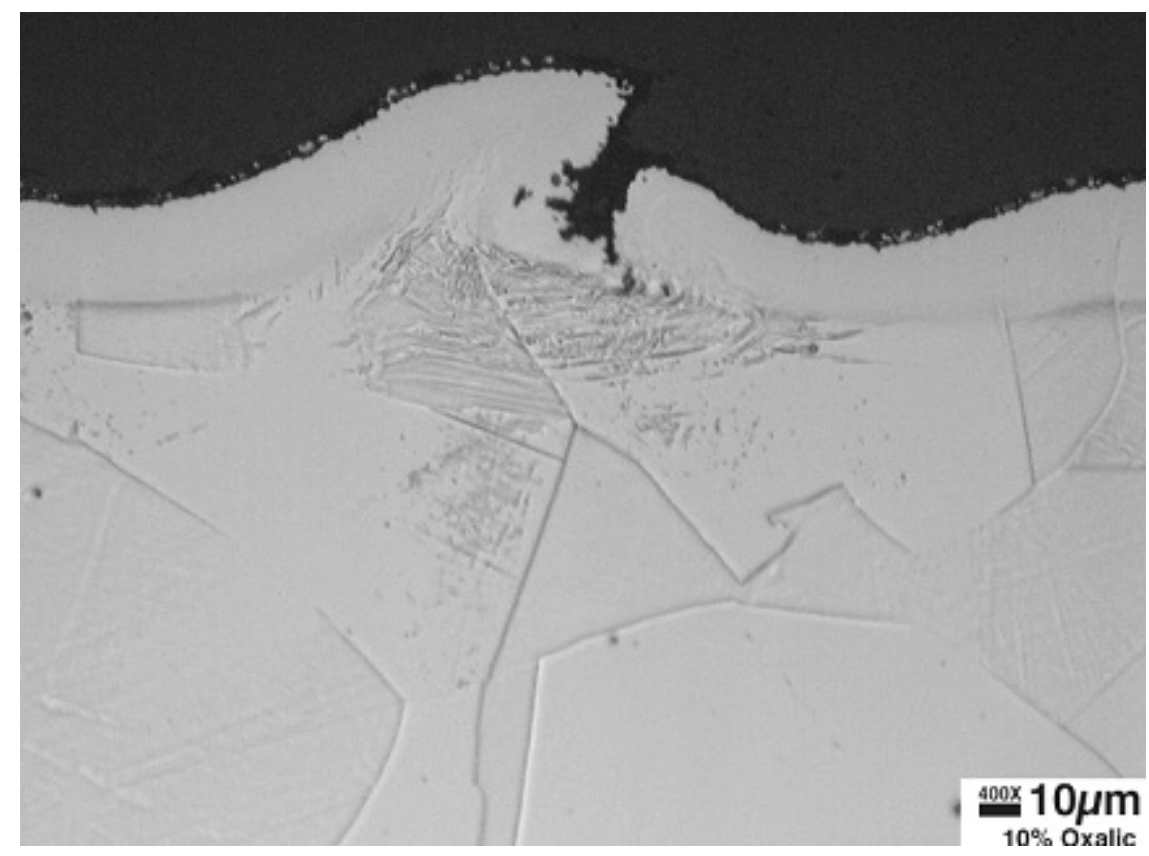

Fig. 13. Crack/pit within the remaining K-layer on the annealed-plus-Kolsterised $\circledast$ " $d$ " specimen following $29 \mathrm{~h}$ sonication. Note the concentration of slip lines in the annealed substrate immediately beneath the near-breach in the K-layer. 


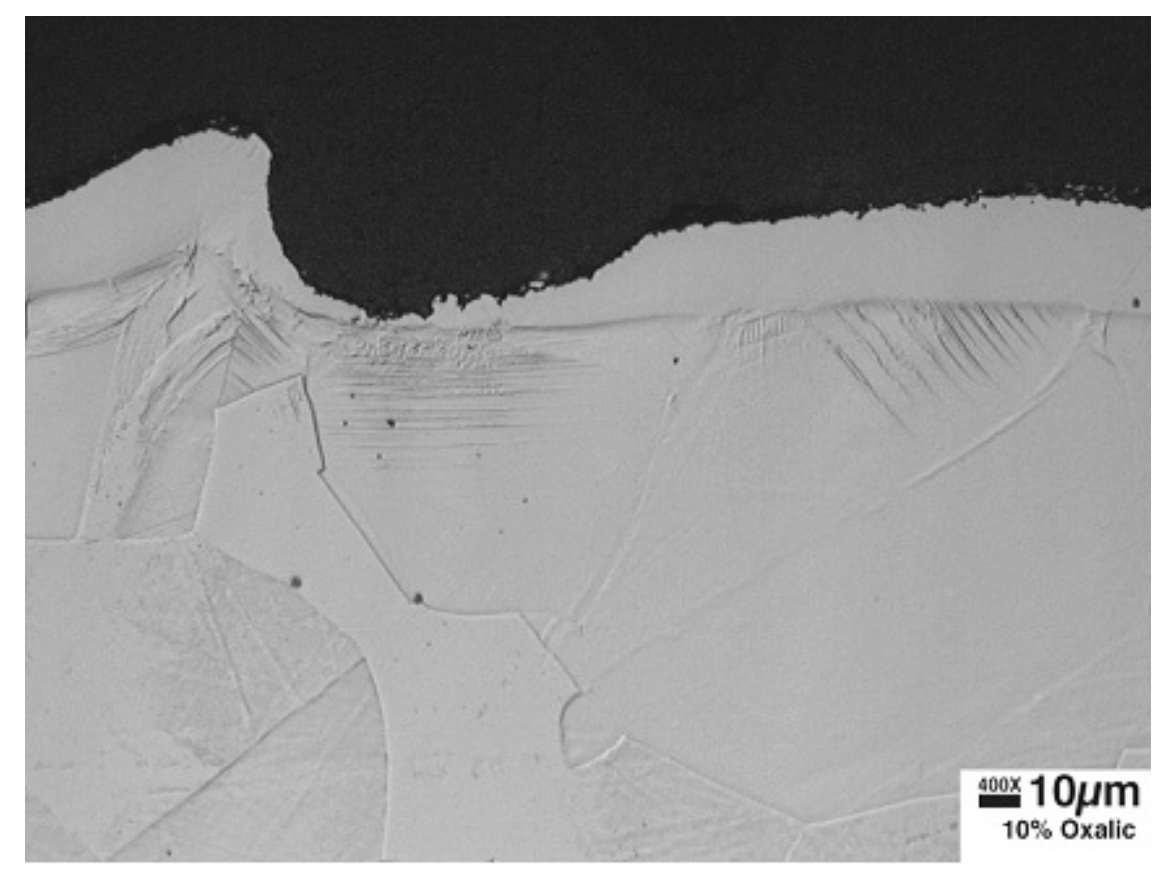

Fig. 14. Pit contained within the remaining K-layer on the annealed-plus-Kolsterised $\AA$ " $d$ " specimen following $29 \mathrm{~h}$ sonication. Note the extent of K-layer removal from the high point to the low point within the layer.

In light of the results for specimens "a," "b," and "d" indicating that only modest departure from the steady-state weight loss rate was associated with the onset of K-layer failure (as evidenced by K-layer thinning and surface cratering), specimen "c" was further sonicated in 2-3 $\mathrm{h}$ increments to a total of $48 \mathrm{~h}$ exposure prior to being sectioned for metallography. Like specimen "d," specimen "c" also exhibited an initial carburized layer thickness of about $40 \mu \mathrm{m}$ on the annealed substrate. Figure 15 shows a sequence of pictures of the test surface of specimen "c" at various intervals during extended sonication. Consistent with Fig. 8, wrinkling and the onset of cratering were observed following 21-24 h exposure. Following $36 \mathrm{~h}$, the specimen surface exhibited substantial general surface roughness and many large craters - generally similar in appearance to an untreated annealed substrate after only 2-3 hours sonication in mercury. Following about $42 \mathrm{~h}$ exposure, the surface had become sufficiently rough and cratered that little additional (macroscopic) change was observed. At the termination of this test (48 h), the weight change rate for specimen "c" was about $5.7 \mathrm{mg} / \mathrm{h}$, which remains less than half of the steady-state weight loss rate observed for the annealed but 
untreated substrate (range of $12-13 \mathrm{mg} / \mathrm{h}$ ), which suggests some residual positive effect of the Kolsterising ${ }^{\circledR}$ treatment.

Figure 16 is a representative cross-section of the post exposure test surface of specimen "c" following $48 \mathrm{~h}$ sonication, and it indicates a surface profile dominated by pits/craters (here, more than $250 \mu \mathrm{m}$ deep). Even following $48 \mathrm{~h}$ exposure, it was observed that regions of Kolsterised $₫$ material remain on the test surface, as evidenced here by the $\sim 20$ um thick layer on the upper left portion of the specimen. That the weight loss rate for this specimen remains less half of the weight loss rate expected from the equivalent untreated specimen suggests that a significant fraction of the test surface retains at least a partially protective Kolsterised $®$ layer thickness after this extended exposure period. Also note that in the higher magnification photograph of Fig. 16, a small region of original substrate (left edge of the pit) devoid of Kolsterised@ layer but only very slightly attacked by the sonication process is apparent. It is likely that this region was only recently exposed due to failure/loss of the coating layer, or more attack at this location would be evident. 


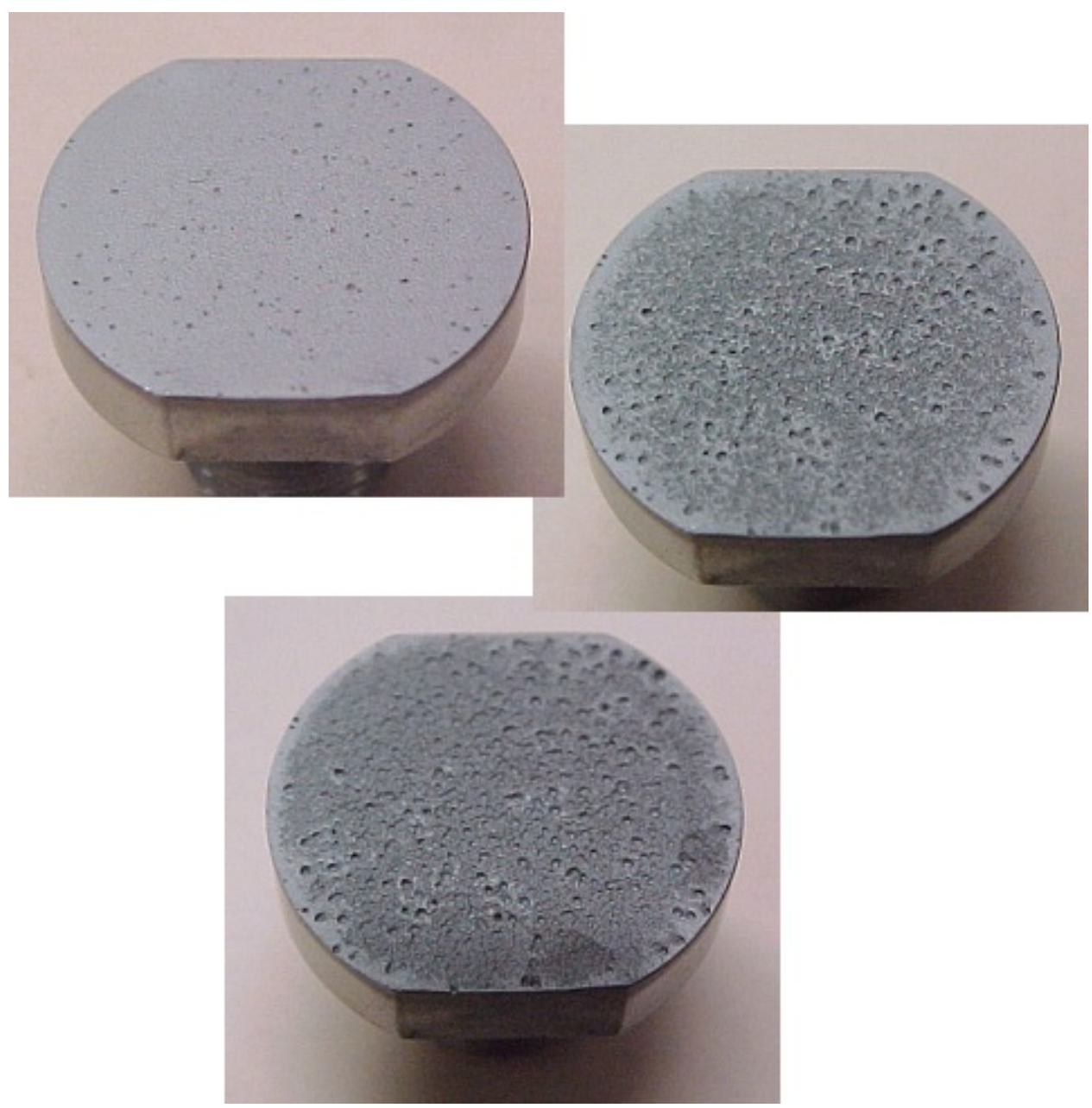

Fig. 15. Annealed-plus-Kolsterised $₫$ specimen "c" following 24-, 36-, and 42-h of sonication in mercury, respectively, clockwise from top left. Actual test surface diameter is $16 \mathrm{~mm}$. 

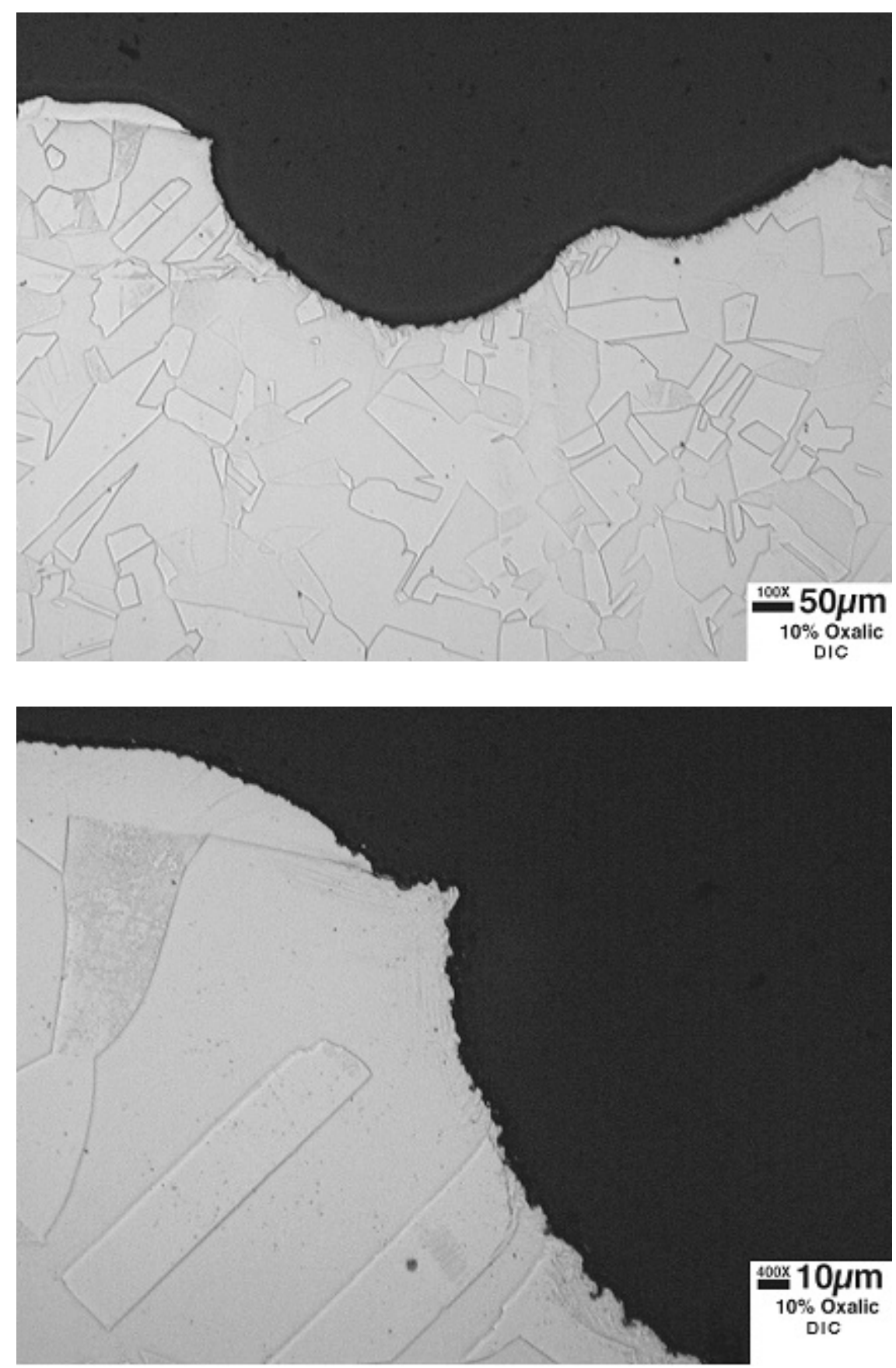

Fig. 16. Etched cross-section of annealed-plusKolsterised $\AA$ specimen "c" following $48 \mathrm{~h}$ sonication in mercury. Note that just to the left of the pit (higher magnification view in bottom photograph), about $20 \mu \mathrm{m}$ of K-layer remains intact. 
Taken together, the results for the annealed substrate specimens suggest that there is a transition from generalized erosion and K-layer thinning to significantly increased surface roughness and the onset of pitting when the remaining K-layer thickness has been reduced to the range of $15-20 \mu \mathrm{m}$. Observations suggesting this "threshold" include the slight increase in weight loss rate as a function of time for specimen "b" at $18 \mathrm{~h}$ exposure (and $20 \mu \mathrm{m}$ K-layer remaining), significant pitting/cratering exhibited on the specimen "a" surface after $30 \mathrm{~h}$ exposure (15 $\mu \mathrm{m}$ K-layer remaining), and significant pitting/cratering exhibited on the specimen "d" surface at $29 \mathrm{~h}$ exposure $(20 \mu \mathrm{m} \mathrm{K}$-layer remaining), while shorter exposures (and thus thicker K-layers) on these specimens yielded much less damage. It is known that the hardness of the K-layer is highest on the outermost surface of treated specimens and drops rapidly with depth into the specimen, ${ }^{1}$ and it is suspected that the surface hardness level is reduced substantially by erosion at the point only approximately $15-20 \mu \mathrm{m}$ of carburized layer remains, thereby reducing resistance to cavitation such that a transition to pitting is observed. It is not apparent, however, what causes craters (as opposed to more uniform erosion) to form at all - it is possible that local variations in hardness or microstructure are involved, as well as geometry effects that focus/accelerate cavitation activity at the first spots to become roughened.

\subsection{LN Stainless Steel with $50 \%$ Cold-Worked Substrate}

Three identical specimens that were machined from $50 \%$ cold-worked material and subsequently received the standard Kolsterising ${ }^{\circledR}$ treatment (resulted in an initial K-layer thickness of about $35 \mu \mathrm{m}$ on each specimen) were also examined for end-of-life characteristics of the protective layer. The weight loss as a function of sonication time for the treated specimens with the cold-worked substrate is presented in Fig. 17. Similar to the case for the specimens with an annealed substrate, the scatter in the weight loss results among the Kolsterised $\circledast$ cold-worked specimen was very modest, and a steady-state weight loss rate essentially identical to that for the specimens with an annealed substrate $(0.7-0.8 \mathrm{mg} / \mathrm{h})$ was observed. At the maximum of the specimen "c" exposure, the weight loss rate increased to about $3.2 \mathrm{mg} / \mathrm{h}$, or about $75 \%$ of the expected weight loss rate $(4.4 \mathrm{mg} / \mathrm{h})$ for the equivalent untreated $50 \%$ cold-worked substrate. Note that even after almost $36 \mathrm{~h}$ sonication, specimen "b" in this set had not yet deviated significantly from the steady-state weight loss rate observed for these specimens. 


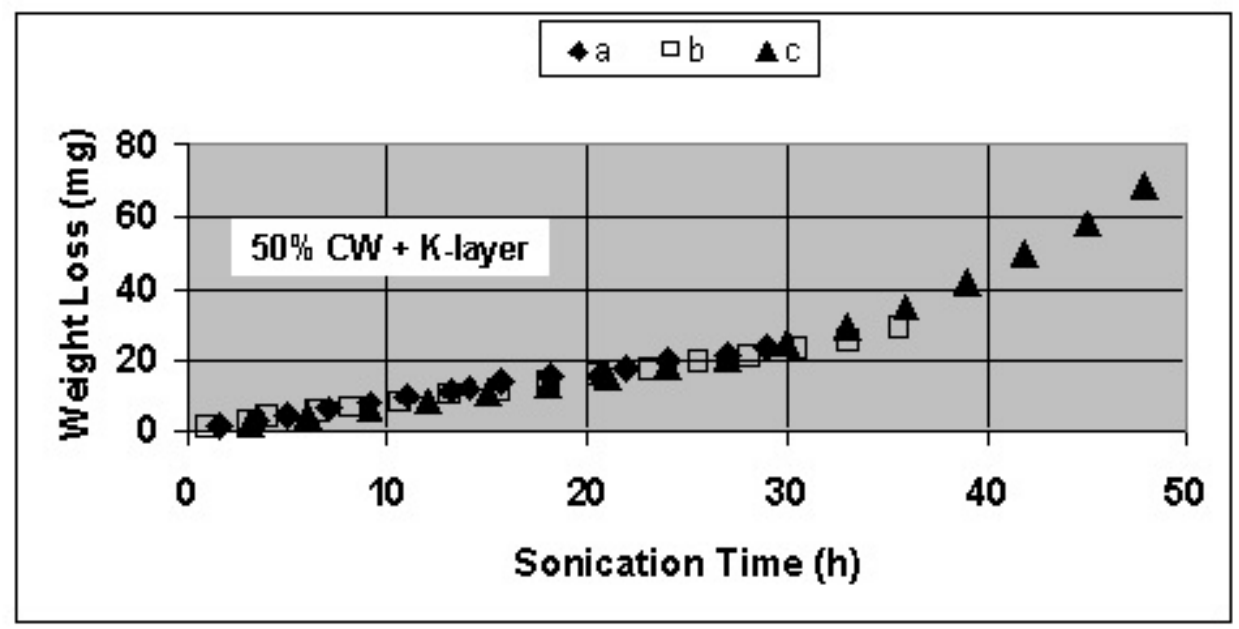

Fig. 17. Weight loss as a function of sonication time for specimens of $50 \%$ cold-worked $316 \mathrm{LN}$ that received the standard Kolsterisation ${ }^{\circledR}$ treatment.

Figure 18 shows a sequence of photographs representing the change in the test surface appearance as a function of sonication time for the treated specimens with a cold-worked substrate. For exposure times up to 20-22 h, each specimen in this set was observed to exhibit only 2-4 modest pits on an otherwise smooth and featureless surface. After 26-28 h exposure, more numerous (and deeper) pits were commonly observed. At longer exposure times (but greater than for the equivalent specimens with an annealed substrate), more and more of the test surface became wrinkled and eventually cratered. 


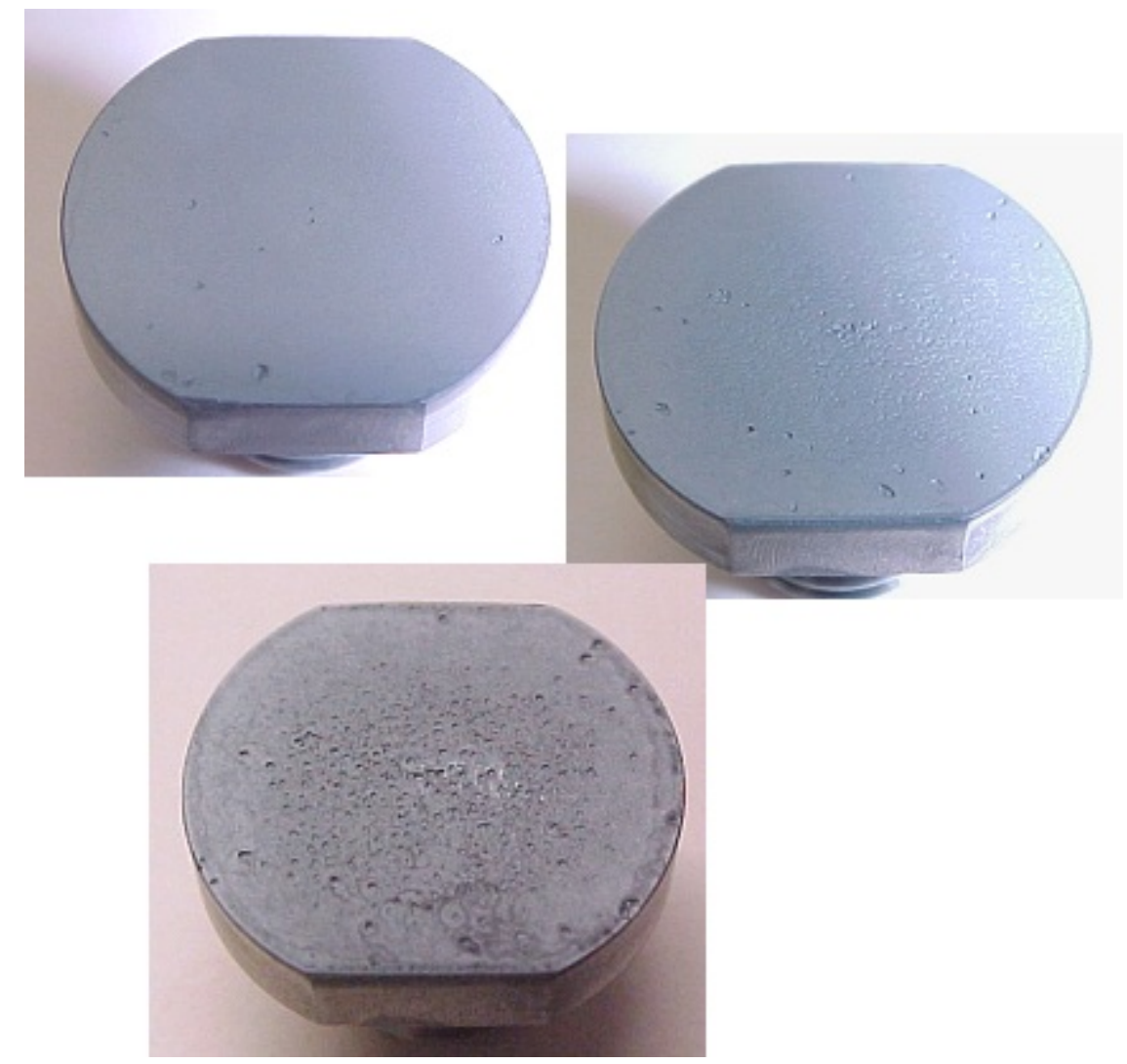

Fig. 18. Test surface of Kolsterised $®$ specimens with a cold-worked substrate exposed to sonication in mercury for $27 \mathrm{~h}, \mathbf{3 3} \mathrm{h}$, and $\mathbf{4 2} \mathrm{h}$, clockwise from top left. Actual specimen diameter for all buttons was $16 \mathrm{~mm}$.

Figures 19 and 20 are representative of the pitting observed on specimens with a cold-worked substrate following extended exposures. In particular, Fig. 19 shows cold-worked/treated specimen "a" following $29 \mathrm{~h}$ exposure - prior to serious deviation from the steady-state weight loss rate shown in Fig. 17. It reveals a remarkably smooth and uniform surface interrupted by a single pit. The average remaining K-layer thickness on this specimen at this apparent onset of pitting was determined to be 19-20 $\mu \mathrm{m}$, which is very similar to the "threshold" result observed for the onset of pitting in treated specimens with an annealed substrate. As a rule, however, it was observed that the cold-worked substrate specimens yielded far fewer - and generally much more shallow - pits during the same exposure time as specimens with an annealed substrate. Note that the cold-worked substrate does not eliminate the displacement of the substrate via formation of a "lip" at the edge of the cavitation crater (Fig. 19). In addition, the 
bottom of the pit reveals a roughened surface similar to that observed for specimens with an annealed substrate. Figure 20 shows a similar cross-section of the "c" specimen with a cold-worked substrate following $48 \mathrm{~h}$ sonication. Again, the bulk surface remained relatively smooth but only small areas with residual K-layer were observed. The similarity in size/shape of the craters in the cold-worked substrate with those in the annealed substrate is striking and is a testament to the power in the cavitation process that similarly pits materials with substrates as hard as $340 \mathrm{DPH}$ (Rc 35).
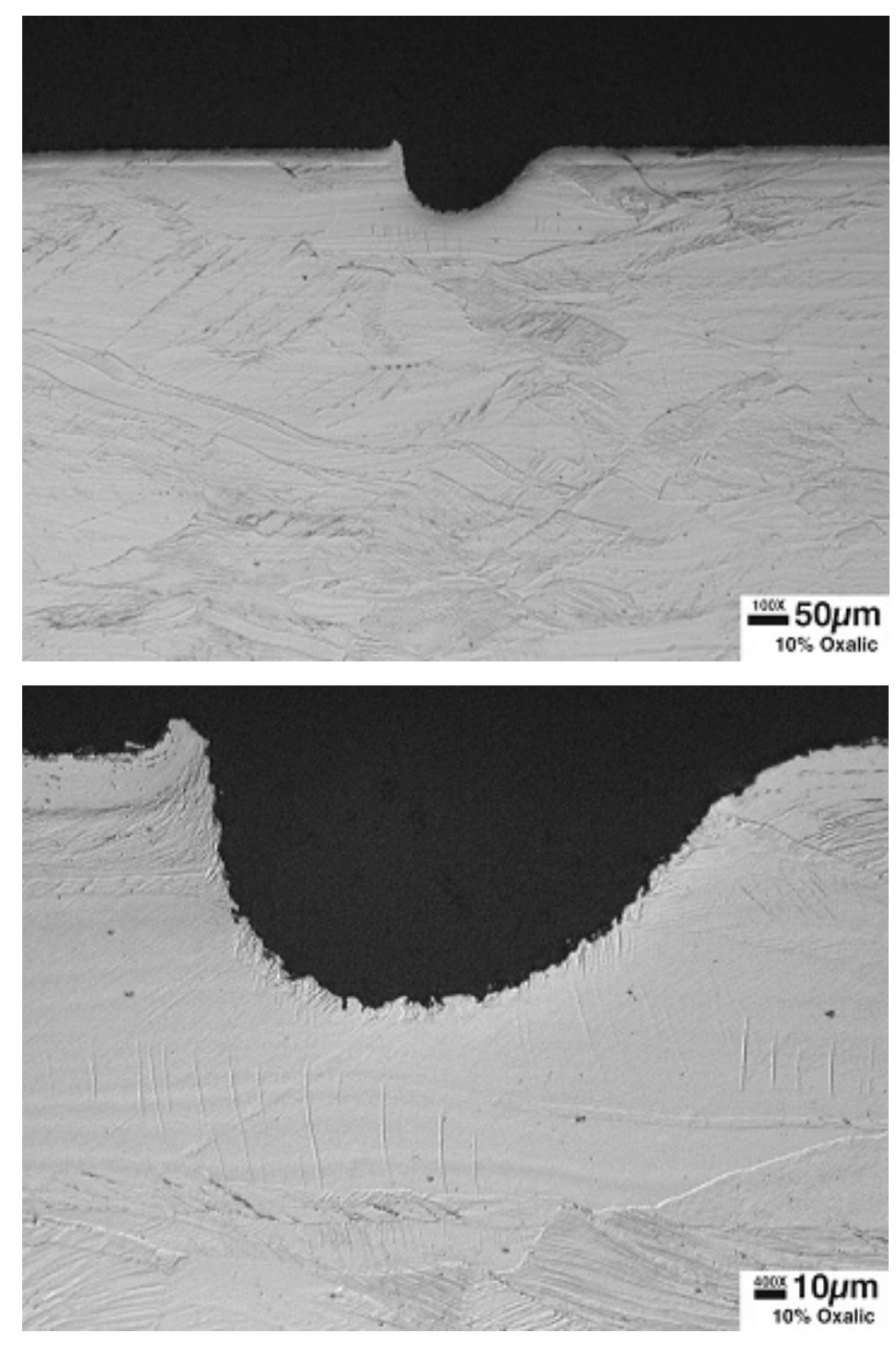

Fig. 19. Etched cross-section of cold-worked and Kolsterised $\circledast$ specimen " $a$ " following $29 \mathrm{~h}$ sonication. 

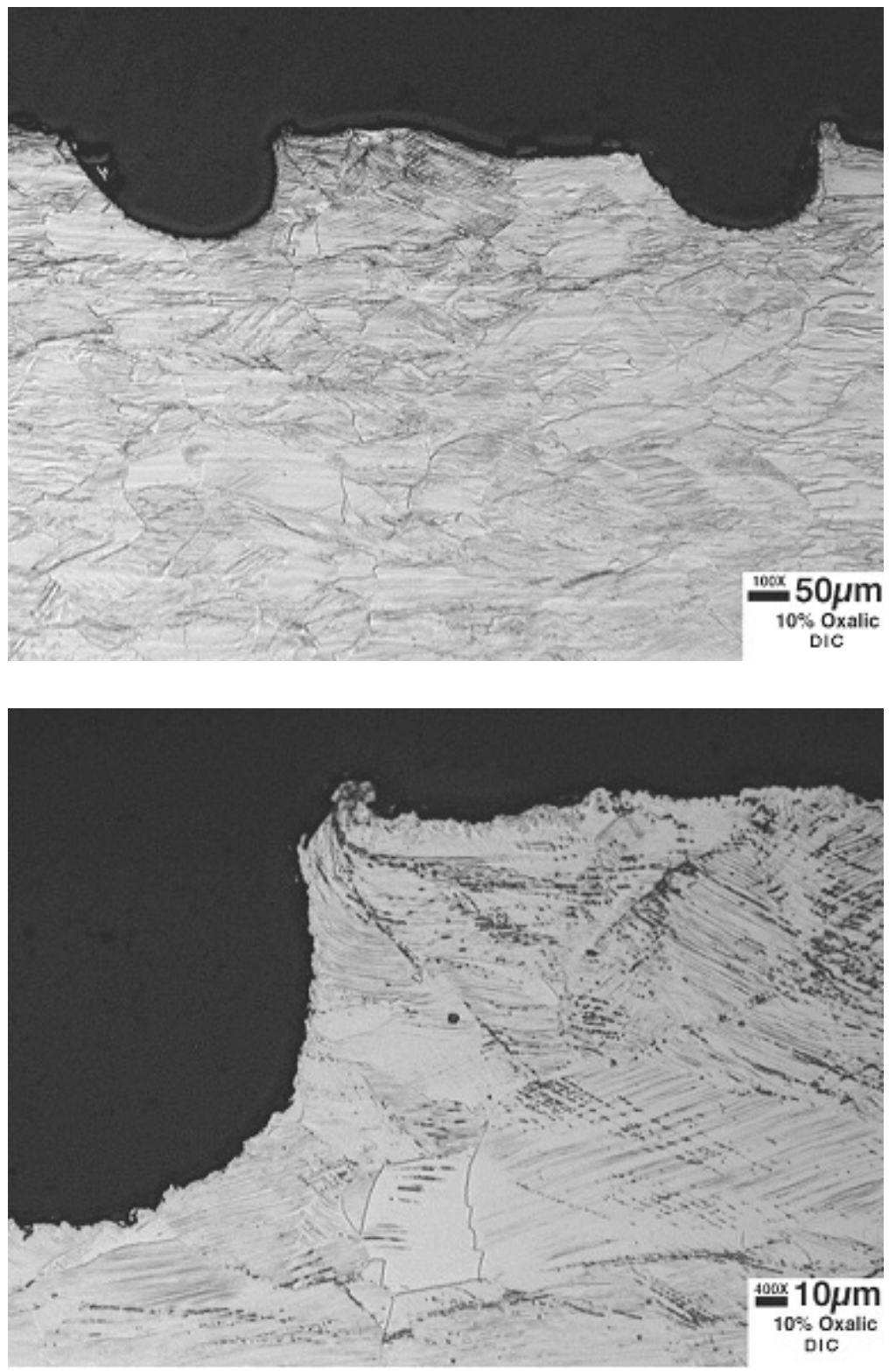

Fig. 20. Etched cross-section of cold-worked and Kolsterised $\circledast$ specimen " $c$ " following $48 \mathrm{~h}$ sonication in mercury.

Figure 21 shows a comparison of the weight loss results for the two specimens with the longest exposure times in this evaluation; that is, annealed substrate specimen "c" with an initial K-layer thickness $40 \mu \mathrm{m}$, and cold-worked substrate specimen "c" with an initial K-layer thickness of $35 \mu \mathrm{m}$. Graphed in this fashion, it is easy to see that the 
steady-state weight loss rate for each specimen type is essentially identical. Although limited in number, remaining K-layer thickness measurements as a function of sonication time collected via metallography confirm this trend. The similarity in the steady-state weight loss and K-layer thinning rates for the two different substrates suggests general erosion is primarily controlled by the properties of the K-layer itself as opposed to the properties of the substrate. However, note that as the K-layer is degraded by thinning and cavitation damage begins to accumulate in both the remaining $\mathrm{K}$-layer (thinned to less than 15-20 $\mu \mathrm{m}$ ) and the adjacent substrate, the average mass loss rate and the average surface profile both become much greater much faster for the K-layer on the annealed substrate.

In addition to data on the average surface roughness as a function of sonication time included in Fig. 21, the depth of a few individual pits on the surface of each specimen was also tracked as a function of sonication time. For both the annealed/treated specimens as well as the cold-worked/treated specimens, pit depth increased slowly only about $2 \mu \mathrm{m} / \mathrm{h}$ or less - until the pit depth reached approximately 30-35 $\mu \mathrm{m}$. Beyond this depth, the K-layer was either breached or sufficiently thinned that its protective ability was compromised and the pit growth rate accelerated. On the annealed substrate specimens, pits were found to increase in depth at an average rate in the range of approximately $5-9 \mu \mathrm{m} / \mathrm{h}$ following breach of the $\mathrm{K}$-layer, while the rate for specimens with a cold-worked substrate was only 3-6 $\mu \mathrm{m} / \mathrm{h}$. In each case, these rates are roughly consistent with the rate of change in average roughness of the bulk surface following the departure from steady-state change associated with a protective K-layer. For both substrates, however, pit depth did not necessarily increase uniformly with time. Rather, there was significant variability and even occasional exposure periods during which the pit depth did not measurably increase followed by a period in which the pit depth increased significantly more than the average rate. This behavior may have occurred across the entire surface, but individual pits in specific locations on the specimen surface lend themselves to trending this pattern, while more generalized areas on the specimen surface do not. In any case, these data suggest that the cavitation-erosion process on the test surface of vibratory horn specimens is somewhat random in that damage is not necessarily focused at existing flaws/pits - otherwise, the pits would grow deeper at a rate much faster than the change in the average profile of the surface. That there are periods during which existing pits do not change depth appreciably is curious but nevertheless a reproducible observation in the vibratory horn testing. 


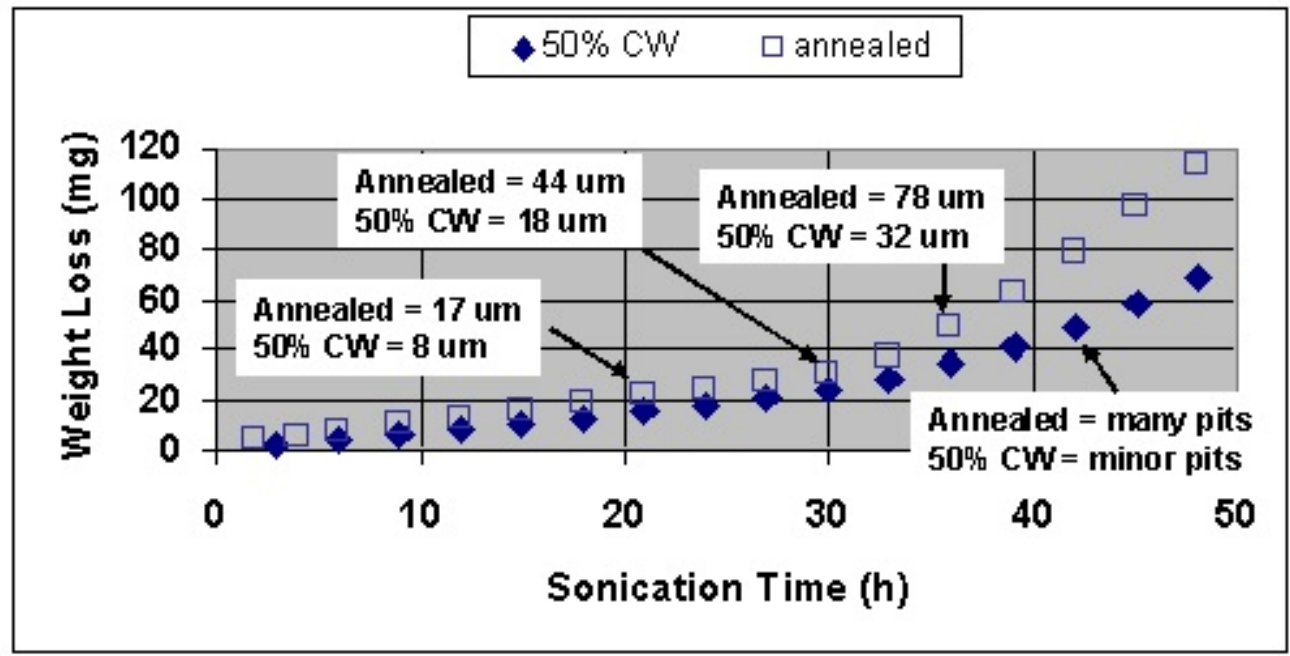

Fig. 21. Weight loss as a function of sonication time for annealed/Kolsterised $₫$ specimen "c" and cold-worked/Kolsterised $₫$ specimen "c." Average surface profile is given for each specimen at equivalent exposure durations denoted by the arrows. 


\section{CONCLUSIONS}

The Kolsterised $®$ layer on both annealed and cold-worked substrates of $316 \mathrm{LN}$ stainless steel remains protective - as evidenced by relatively modest steady-state weight loss and surface roughness increases, only very isolated pitting, and limited wetting by mercury - until the K-layer is thinned by general erosion to a remaining thickness of $15-20 \mu \mathrm{m}$ (corresponding to about $20 \mathrm{~h}$ or more of sonication time in mercury using the vibratory horn procedure described here). The cavitation-erosion resistance of the K-layer at this thickness is sufficiently reduced compared to that of the original surface of the K-layer - i.e., hardness has been reduced below a critical "threshold" limit - that cavitation-erosion accelerates significantly with continued sonication.

The initial K-layer breakdown is characterized by an increase in the general surface roughness and the development of discrete pits as opposed to generalized failure across the entire surface. The surface roughness and number/depth of individual pits both become greater at a rate that is strongly dependent on the substrate condition, with the softer annealed substrates significantly more susceptible to damage. Continued sonication eventually tends to consume the K-layer across the specimen surface resulting in overlapping pits/craters as larger fractions of the test specimen surface are left exposed without any protective layer. Both weight change and profile development as a function of sonication time suggest a very slow/gradual reversion to cavitationerosion behavior similar to that observed for the untreated substrates as the fraction of K-layer removed increases. Even at $48 \mathrm{~h}$ exposure $\left(\sim 3.5 \times 10^{9}\right.$ cavitation cycles $)$, weight loss rates less than those for untreated substrates were observed, suggesting continued influence of both the thin portions of remaining $\mathrm{K}$-layer and the local strain hardening resulting from the process treatment.

Because the rate of general erosion/thinning of the K-layer seems independent of its original thickness in the $32-40 \mu \mathrm{m}$ range and the transition from modest generalized erosion to significant surface roughening and pitting occurs when the remaining K-layer thickness has been reduced to a fixed value near 15-20 $\mu \mathrm{m}$, a practical strategy to increase cavitation-erosion resistance and/or the duration such resistance is retained may be to adjust the carburization treatment to generate a somewhat thicker casehardened layer. Further study of surface hardness profiles correlated to cavitation resistance in vibratory horn (or other) testing could suggest an optimum process 
treatment for $316 \mathrm{LN}$ stainless steel and direct life prediction estimates. The additional cavitation resistance imparted by having a cold-worked substrate is substantial and should be incorporated where possible to maximize performance. 


\section{ACKNOWLEDGMENTS}

The author gratefully acknowledges the contribution of several other individuals to this research and report. Funding for the effort was provided through work managed by B. W. Riemer from the Spallation Neutron Source Project at Oak Ridge National Laboratory, who also arranged for the surface treatment of the specimens. H. F. Longmire performed the metallography of the cavitation buttons. J. D. Hunn and P. F. Tortorelli reviewed the manuscript. F. C. Stooksbury helped prepare and distribute the document. 



\section{REFERENCES}

1. K. Farrell, et al., "Characterization of a Carburized Surface Layer on an Austenitic Stainless Steel," J. Nucl. Mater. 343 (2005) 123-133.

2. S. J. Pawel, "Assessment of Cavitation-Erosion Resistance of 316LN Stainless Steel as a Function of Surface Treatment," J. Nucl. Mater. 343 (2005) 101-105.

3. S. J. Pawel and E. T. Manneschmidt, "Preliminary Evaluation of Cavitation Resistance of Type 316LN Stainless Steel in Mercury Using a Vibratory Horn," J. Nucl. Mater., 318 (2003) 122-131.

4. S. J. Pawel and L. K. Mansur, "Evaluation of Cavitation-Erosion Resistance of 316LN Stainless Steel in Mercury Containing Metallic Solutes," Oak Ridge National Laboratory Technical Memorandum ORNL/TM-2006/539, August 2006. [Also: Proceedings of the $8^{\text {th }}$ International Workshop on Spallation Materials Technology (IWSMT-8), Taos, NM, October 16-20, 2006 and submitted for publication in a special edition of $J$. Nucl. Mater.].

5. S. J. Pawel, Comparison of Cavitation-Erosion Resistance of Carburized and Carburized-Plus-Nitrided 316LN Stainless Steel in Mercury, Oak Ridge National Laboratory Technical Memorandum ORNL/TM-2007/058, May 2007.

6. Standard Test Method for Cavitation Erosion Using Vibratory Horn Apparatus, ASTM G-32-98, American Society for Testing and Materials, Philadelphia, PA, 1998, p.109. 



\section{INTERNAL DISTRIBUTION}
1. P. J. Blau
2. D. C. Lousteau
3. L. K. Mansur
4. T. J. McManamy
6-8. S. J. Pawel
9. B. A. Pint

\author{
10. B. W. Riemer \\ 11. M. W. Wendel \\ 12. D. F. Wilson \\ 13. S. J. Zinkle
}

14. Central Research Library

15. ORNL Laboratory Records-RC 
